\title{
LA DESEABLE COMPOSICIÓN PARITARIA DEL TRIBUNAL CONSTITUCIONAL: UNA PROPUESTA DE REFORMA CONSTITUCIONAL
}

OCTAVIO SALAZAR BENÍTEZ 
SUMARIO

1. INTRODUCCIÓN: INGENIERA JURÍDICA VS. CULTURA POLÍTICA. 2. EL NOMBRAMIENTO DE LOS MAGISTRADOS Y LAS MAGISTRADAS.

2.1. La reconocida competencia — ¿también desde el punto de vista del género? - de quienes componen el Tribunal Constitucional. 2.2. El método de elección. 2.3. El retraso en las renovaciones de Tribunal. 3. LA COMPOSICIÓN DEL TRIBUNAL CONSTITUCIONAL DESDE EL PUNTO DE VISTA DEL GÉNERO. 3.1. La desequilibrada composición del Tribunal Constitucional. 3.2. Las escasas referencias comparadas; 3.3. Una cuestión de paridad. 4. CONCLUSIONES Y PROPUESTAS. 


\title{
LA DESEABLE COMPOSICIÓN PARITARIA DEL TRIBUNAL CONSTITUCIONAL: UNA PROPUESTA DE REFORMA CONSTITUCIONAL
}

\author{
OCTAVIO SALAZAR BENÍTEZ
}

\section{INTRODUCCIÓN: INGENIERÍA JURÍDICA VS. CULTURA POLÍTICA ${ }^{2}$}

En los últimos años ha sido recurrente el debate en torno a la progresiva pérdida de prestigio del Tribunal Constitucional (en adelante, TC) y a las consecuencias negativas que ello está teniendo para la «salud» de nuestro sistema ${ }^{3}$. No cabe ninguna duda de que un punto de inflexión con respecto a lo que durante las primeras décadas de democracia había constituido una trayectoria solida y casi unánimemente reconocida, por más que algunas de sus decisiones pudieran ser lógicamente controvertidas, lo constituyó la sentencia que resolvió el recurso de inconstitucio-

${ }^{1}$ Catedrático de Derecho Constitucional de la Universidad de Córdoba. Facultad de Derecho y Ciencias Económicas y Empresariales. C/Puerta Nueva s/n. 14071 Córdoba (España). N. ${ }^{\circ}$ ORCID: 00000002-1294-8662, G.I. SEJ-372, DEMOCRACIA, PLURALISMO Y CIUDADANÍA.

2 El título de este capítulo es deudor de la expresión usada por J. Pérez Royo al referirse a los problemas que plantean en la práctica tanto el art. 159.3 CE como el art. 17 LOTC y que según el catedrático sevillano no pueden ser resueltos mediante «ingeniería constitucional». PÉrEZ RoYo, J. (2011), «Encuesta sobre la renovación del Tribunal Constitucional», Teoría y Realidad constitucional, n. ${ }^{\circ} 28,2^{\circ}$ semestre, p. 78 .

3 De hecho, ya en 1999 hubo quien afirmó de manera tajante que «el período de la autocomplacencia y satisfacción generalizadas respecto de lo que fue la joya de la Corona se ha acabado». GARCía RocA, J. (1999), "Cuestionario sobre la reforma de la LOTC», Teoría y Realidad constitucional, n. ${ }^{\circ}$, $2 .^{\circ}$ semestre, p. 20. Incluso se ha llegado a afirmar que «el caudal de enorme prestigio acumulado por el Tribunal en sus primeros años de funcionamiento ha ido degradándose hasta límites inquietantes. FÉrnandez Miranda, A. (2011), «Encuesta sobre la renovación del Tribunal Constitucional», cit., p. 23. 
nalidad contra la reforma del Estatuto de autonomía de Cataluña ${ }^{4}$. Pero es evidente que no solo esa polémica decisión ha contribuido a la pérdida de autoridad y de prestigio del TC.

Junto a las críticas que con todo merecimiento han merecido cuestiones relativas a sus funciones ${ }^{5}$, han jugado un papel esencial en esta progresiva pérdida de prestigio las cuestiones relativas a sus miembros y «miembras» ${ }^{6}$. Es decir, no cabe duda de que un factor clave en la pérdida de auctoritas del TC ha sido el hecho de que los partidos políticos hayan convertido los nombramientos y renovación de magistrados/as del TC en parte de su «juego político», con las consiguientes dificultades y retrasos en las designaciones y con la negativa consecuencia de trasladar a la opinión pública la idea de que sus integrantes no son tanto juristas de reconocida competencia que actúan con independencia sino más bien sujetos y sujetas dependientes de los intereses partidistas. Ello ha llevado a que, por ejemplo, los medios de comunicación insistan en la identificación de los/as magistrados/as con el partido que lo propuso o a que se perciba que el TC funciona dividido en dos bloques ideológicos, por lo que el fallo en determinados asuntos se ha vinculado directamente con la posición política mayoritaria en el órgano. Todo esto ha llevado también a cuestionar, por ejemplo, el voto de calidad de la Presidencia que es la que decide en los supuestos de empate ${ }^{7}$.

Sirva como ejemplo la reciente renovación de los 4 magistrados/as que correspondía hacer al Senado al haber expirado el mandato de otros tantos en diciembre de $2016^{8}$. A pesar del inicial peso de las Asambleas autonómicas en la propuesta, finalmente fueron los intereses de los dos partidos mayoritarios los que acabaron predominando sobre los territoriales? ${ }^{9}$. En este caso, los dos partidos mayoritarios, y a pesar

4 Pérez Royo, J. (2011), cit., p. 41.

5 Podríamos citar, entre otros objetos de crítica, los siguientes: el retraso excesivo en resolver determinados recursos; el desbordante número de recursos de amparo, que solo de manera muy parcial ha reducido la reforma de su tramitación llevada a cabo en 2007; el «choque» con el Tribunal Supremo ante algunas decisiones en las que parecía no estar muy claro quién debía tener la última palabra o, en general, el papel tan complejo que ha tenido que desempeñar en cuanto a la concreción del modelo territorial apenas esbozado en la Constitución de 1978 (en adelante, CE).

${ }^{6}$ Utilizo el término «miembras» con toda la intencionalidad ya que, aunque no está recogido en el Diccionario de la Real Academia de la Lengua — a pesar de que resulta extraño que ante una palabra que hace el masculino en «o» no se permita la construcción del femenino con una «a» final—, es el que mejor nos puede servir para visibilizar la composición en términos de género del TC.

7 De ahí que incluso se hayan llegado a hacer propuestas sobre la necesidad de que el número de componentes del órgano, limitado por el art. 159.1 CE a 12, fuera impar para evitar dicha tesitura. Por ejemplo, S. García Couso propone que el número de magistrados se reduzca a nueve. García Couso, S. (2012) «Cómo superar la lógica del Estado de partidos en el Tribunal constitucional: la reforma del art. 159 CE», Teoría y Realidad constitucional, n. ${ }^{\circ} 29$, p. 450.

${ }^{8}$ La renovación de 4 magistrados a propuesta del Senado en diciembre de 2016 obedeció al reajuste que provocó la reforma de la LOTC llevada a cabo en 2010. En este caso los 4 magistrados no serían renovados el 12 de enero de 2020, nueve años después de su designación, sino el 17 de diciembre de 2016, nueve años después de la fecha en que hubiera debido llevarse a cabo su nombramiento (2007).

9 Baste con recordar algunos de los titulares con los que los medios de comunicación informaron del proceso: PP y PSOE ultiman un pacto para renovar el Tribunal Constitucional (http://politica.elpais.com/ 
de que la composición actual del Parlamento es mucho más plural que en legislaturas anteriores, se repartieron a partes iguales los puestos vacantes ${ }^{10}$.

En este contexto de progresiva pérdida de legitimidad llama la atención que, junto a las evidentes y oportunas críticas que reiteradamente se han realizado sobre el protagonismo de los partidos políticos en las renovaciones del TC, apenas si se haya llamado la atención, con alguna excepción que comentaremos más adelante, sobre la escasa presencia de mujeres en dicho órgano. Un déficit que si bien podría tener una cierta explicación en los primeros años de funcionamiento del Tribunal, en la actualidad debería ocupar un lugar central en los reparos que deberíamos plantear a la composición de un órgano que, de entrada, debería responder a una composición equilibrada, tal y como lo demanda con carácter general la LO 3/2007, de 22 de marzo, para la igualdad efectiva de mujeres y hombres (en adelante, LOIMH). Una composición equilibrada que, además, tendría una singular fuerza simbólica al tratarse de un órgano central en la arquitectura de nuestro sistema y que, en cuanto garante de la supremacía de la Constitución y por tanto de los valores que incorpora, debería responder al principio de paridad. Un principio que debería incorporarse como uno de los estructurales del Estado en una hipotética reforma constitucional y que, por tanto, debería proyectarse tanto en la parte orgánica como dogmática de la Constitución ${ }^{11}$.

Con carácter previo a la formulación de dicha propuesta, repasaremos todas las consideraciones críticas que plantea el actual sistema de nombramiento de la magistratura constitucional. Sin ánimo de exhaustividad, ya que se trata de un tema suficientemente abordado por la doctrina en los últimos años ${ }^{12}$, pretendo con dicha

politica/2017/01/24/actualidad/1485284749_765059.html, consultada: 03/03/17); PP y PSOE se aferran a sus cuotas en el Constitucional (http://www.elmundo.es/espana/2017/03/01/58b6d884268e3ed24d8b4639.html, consultada: 05/03/17); PP y PSOE oficializan el reparto para el Constitucional con dos magistrados para cada uno (http://www.eldiario.es/politica/PP-PSOE-Conde-Pumpido-Tribunal-Constitucional_0_617688941.html, consultada: 05/03/17)

${ }^{10}$ Las dos formaciones mayoritarias aprobaron en la Comisión de Nombramientos del Senado sin votos en contra que dos de los magistrados elegidos lo fueran a propuesta del PP — Ricardo Enríquez (que ya estaba en el TC) y Alfredo Montoya - y otros dos del PSOE - Cándido Conde-Pumpido y María Luisa Balaguer. Véase la propuesta que realiza la Comisión con fecha de 1 de marzo de 2017, después de la comparecencia de un total de 15 candidatos/as: http://www.senado.es/legis12/publicaciones/pdf/ senado/bocg/BOCG_D_12_65_598.PDF (consultada: 10/10/17)

${ }^{11}$ En este sentido, véase la propuesta de pautas para una reforma constitucional con perspectiva de género que ha planteado la Red Feminista de Derecho Constitucional (http://feministasconstitucional. org/wp-content/uploads/2017/12/RFDC_posicionamiento_RefConst-4-diciembre-2017..pdf, consultada: $14 / 12 / 17)$

${ }_{12}$ Véase como completo análisis del mismo la reciente publicación de Estrada MArún, J.A. (2017), La designación de los magistrados del Tribunal Constitucional en España. Una perspectiva orgánica y empírica. Thomson Reuters, Aranzadi, Cizur Menor. Sobre la misma cuestión, cabe recordar las reflexiones de ALZAGA VILLAMIL, O. (2003), «Sobre la composición del Tribunal Constitucional», Teoría y Realidad Constitucional, n. ${ }^{\circ}$ 10-11, pp. 149-180; RUBIO LLORENTE, F. (2004), «El Tribunal Constitucional», Revista Española de Derecho Constitucional, n. ${ }^{\circ}$ 71, pp. 11-33; CRUZ VILLALÓN, P. (2009), «El estado del Tribunal Constitucional», Claves de Razón Práctica, n. ${ }^{\circ}$ 191, pp. 4-12. 
exposición poner en evidencia no solo la rotundidad de las críticas sino también la variedad de las propuestas alternativas, singularmente imaginativas algunas, que se han planteado. Pretendo que todo ello sirva de contraste con la escasa o nula atención prestada a la composición casi exclusivamente masculina del Tribunal, así como a la necesidad de que las personas que compongan dicho órgano acrediten una «reconocida» competencia también en materia de género. Dos aspectos que, conjuntamente, incidirían finalmente no solo en la mayor legitimidad de la jurisdicción constitucional sino también en una mayor capacidad del Tribunal para ajustarse a una sociedad en la que convivimos mujeres y hombres. Un objetivo que, entiendo, debería ser central no solo en los análisis críticos que hagamos cuando la Constitución cumpla 40 años sino también ante las propuestas de la que muchas y muchos consideramos necesaria y urgente reforma.

\section{EL NOMBRAMIENTO DE LOS MAGISTRADOS Y LAS MAGISTRADAS}

\subsection{La reconocida competencia — ¿también desde el punto de vista del género? - de quienes componen el Tribunal Constitucional}

La CE deja claro en los tres primeros apartados de su art. 159 quiénes pueden proponer los candidatos/as a magistrados/as de TC, qué requisitos han de satisfacer las candidaturas y cuándo se procederá a su nombramiento. Siguiendo el modelo mayoritario en Europa, el art. 159.1 CE opta por reenviar a los tres poderes del Estado la propuesta, lo cual, en líneas generales, ha sido bien valorado, aunque efectivamente todas y todos seamos conscientes de que «en general no existe composición óptima de ningún órgano constitucional» ${ }^{13}$.

Con respecto a los requisitos que han de cumplirse para ser magistrado/a del $\mathrm{TC}^{14}$, el art. 159.2 establece un triple condicionante: a) la condición de Magistrados y Fiscales, Profesores de Universidad, funcionarios públicos y Abogados; b) la condición de juristas de reconocida competencia; c) los más de quince años de ejercicio profe-

13 Pérez Royo, J. (2011), cit., p. 55.

14 A lo largo del texto usaré términos que sean comprensivos de ambos géneros, salvo cuando cite textualmente las referencias legales que continúan obedeciendo al «universal masculino», aunque entienda que dicho aspecto debería ser objeto de una reforma en la que se optara por términos inclusivos de ambos géneros. En este sentido, debemos recordar que el art. 14 LOIMH incluye entre los criterios de actuación de los poderes públicos: «La implantación de un lenguaje no sexista en el ámbito administrativo y su fomento en la totalidad de las relaciones sociales, culturales y artísticas». Sobre el uso de un lenguaje no sexista en el ámbito jurídico véase BALAGUER Callejón, M. ${ }^{a}$ L. (2008), «Género y lenguaje. Presupuestos para un lenguaje jurídico igualitario», Revista de Derecho Político, n. ${ }^{\circ}$ 73, septiembre-diciembre 2008, pp. 71-100. 
sional $^{15}$. Para garantizar la independencia del órgano, de manera que no haya una correspondencia plena en el tiempo entre sus componentes y las instancias que los propusieron, el art. 159.3 CE dispone que la designación se lleve a cabo por un período de nueve años y que se renueve por terceras partes cada tres. Con respecto a quiénes pueden ser parte del TC, el art. 18 LOTC añade un requisito que no aparecía concretado en la CE — «ciudadanos españoles»— y puntualiza el relativo al ejercicio profesional ya que establece la alternativa de «más de quince años de ejercicio profesional»o «en activo en la respectiva función» ${ }^{16}$.

Sin duda, uno de los factores que tienen una mayor incidencia en el prestigio y la autoridad del TC es el perfil de las personas seleccionadas como magistradas ${ }^{17}$. Además de los requisitos profesionales exigidos, que obviamente son más fáciles de objetivar, es mucho más complejo concretar qué se entiende por «reconocida competencia». De entrada se plantea el dilema de si el simple ejercicio profesional durante más de 15 años otorga esa competencia o si por el contrario ha de tenerse en cuenta un plus, lo cual lógicamente nos lleva a plantearnos el papel que han de jugar quiénes tienen la capacidad de seleccionar a las personas que ocuparán la magistratura constitucional y que por tanto habrían de tener un celo singular en la selección. Es en este punto donde con frecuencia se ha cuestionado más el perfil de las personas elegidas al extenderse entre la opinión pública que más que por su «reconocida competencia» los/as miembros/as de la carrera judicial o profesores/as universitarios/as seleccionados lo son más por sus «conexiones partidistas» que por el peso de su trayectoria como juristas. De nuevo vuelve a plantearse en este tema no solo la independencia de los magistrados/as sino también el eterno debate en torno a si el juicio que han de emitir es jurídico o político. Evidentemente, un/a magistrado/a del TC debería tener la capacidad de analizar cualquier asunto desde una cierta distancia objetiva,

15 A estos requisitos habría que añadir uno de naturaleza discrecional, la idoneidad, que correspondería reconocer a los sujetos legitimados para la propuesta. LuCAs Murillo De La Cueva, P. (2010), «Las mayorías reforzadas y la formación de los órganos constitucionales (Comentarios sobre la actualidad)», Anuario Parlamento y Constitución, n. ${ }^{\circ}$ 13, p. 131.

${ }^{16}$ En la práctica ha planteado confusión el cómputo del requisito temporal del ejercicio profesional, tal y como se evidenció cuando la Mesa del Congreso no admitió a trámite la propuesta de Enrique López como candidato, lo cual llevó a que el Parlamento de la Rioja y la Asamblea de la Comunidad de Madrid plantearan recurso de amparo ante el TC, que fue inadmitido por falta de legitimación (ATC 192 y 193/2010, de 1 de diciembre). De ahí que se hayan hecho propuestas, como la que plantea la siguiente distinción: «Los miembros del Tribunal Constitucional propuestos por el Congreso y el Senado deberán ser nombrados entre Magistrados y Fiscales, Profesores de Universidad y funcionarios públicos y Abogados, todos ellos juristas de reconocida competencia de más de cuarenta años de edad y con más de quince años de ejercicio profesional. Los miembros propuestos por el Consejo General del Poder Judicial de entre Magistrados y Fiscales deberán contar con más de cuarenta años de edad y con más de quince en activo en la carrera judicial o fiscal». GARcía Couso, S. (2012), cit., p. 454-455.

${ }_{17}$ «Es notorio que por el Tribunal han pasado (y están actualmente) muchos de los mejores juristas del país: pero también lo es que han tomado asiento en el mismo contados profesionales a los que jamás hubiéramos encomendado un asunto mínimamente complejo». SANTAmaría Pastor, J.A. (2011), «Encuesta sobre la renovación del Tribunal Constitucional», cit., p. 57. 
partiendo en todo caso de que como cualquier persona no es solo y exclusivamente «la boca de la ley», en este caso diríamos «de la Constitución», sino también un individuo con sus propios criterios éticos, su ideología y, en definitiva, con una determinada mirada sobre la realidad ${ }^{18}$. En este sentido, y mucho más cuando el TC debe enfrentarse a asuntos de contenido altamente político, la imparcialidad, entendida en el sentido jurídico más estricto, difícilmente supera la categoría de mera exigencia formal. Por lo tanto, lo que habría que garantizar mediante una adecuada selección de personas candidatas es que se trate de juristas independientes de intereses e hipotecas partidistas y que tengan las capacidades y habilidades necesarias para llevar a cabo el trabajo que les va a corresponder de interpretar la Constitución ${ }^{19}$. Junto a lo que podríamos considerar elementos curriculares básicos a tener en cuenta, y que serían fáciles de baremar, tal y como se hace en cualquier acceso a la función pública, creo que deberían tenerse presentes otros factores que incidirían en la reconocida competencia de las personas candidatas no simplemente como juristas sino como juristas que han de desempeñar la más alta magistratura en un Estado constitucional. En este sentido, habría que tener muy presente de qué manera la carrera profesional de las personas candidatas refleja un adecuado conocimiento y experiencia en cuestiones relacionadas con las funciones que desempeña el $\mathrm{TC}^{20}$. Así, por ejemplo, habría que valorar de manera singular qué meritos inciden en su experiencia en materia

${ }^{18}$ Es evidente que su propia trayectoria como jurista, avalada por más de 15 años de ejercicio profesionales, pondrá de relieve cuál es justamente su manera de entender el Derecho, los principios constitucionales o la gestión de los conflictos en una sociedad democrática.

19 En este sentido, me parecen muy oportunas algunas de las exigencias que reivindica J. García Roca, tales como «experiencias variadas a la hora de fundar sus decisiones en normas, argumentar con las lógicas de la racionalidad y la proporcionalidad y de otros principios jurídicos, y manejar muy variadas leyes y un amplio caudal de precedentes comparados y de las dos jurisprudencias europeas» o «conocer las líneas principales de la amplísima jurisprudencia creada por la jurisdicción constitucional en tres décadas». GARCíA RoCA, J. (2012), «La selección de los magistrados constitucionales, su estatuto y la necesaria regeneración de las instituciones», Revista General de Derecho Constitucional, 15, p. 16.

${ }^{20}$ Esta dilatada experiencia, de manera singular en el caso de los Magistrados que son elegidos entre miembros de la comunidad universitaria, y que por tanto han llevado a cabo una intensa y prolongada actividad investigadora sobre temas «inevitablemente constitucionales», debe constituir por lo tanto un dato objetivo que avale el prestigio y la autoridad de los componentes del TC. De ahí que no pueda parecernos sino descabellada la recusación del magistrado Pérez Tremps, planteada al hilo del recurso de inconstitucionalidad contra la reforma del Estatuto catalán, el cual se consideró que no satisfacía las exigencia de imparcialidad necesarias al haber realizado un trabajo académico sobre la participación de las Comunidades Autónomas en la Unión Europea. Una decisión, plasmada en el ATC 26/2007, de 5 de febrero, que contó con cinco votos particulares, y que nos llevaría al absurdo de excluir la participación de cualquier profesor o profesora de Derecho Público que a lo largo de su trayectoria como investigador se hubiera pronunciado sobre algún tema que tuviera que dirimir el TC. Una decisión absurda porque es justamente por esa trayectoria por la que se supone que ese concreto profesor ha sido designado como Magistrado. Sobre este tema véase DELGADO RINCÓN, L.E. (2008), «La recusación de los Magistrados del Tribunal Constitucional (Comentario al ATC 26/2007, de 5 de febrero)», Revista Española de Derecho Constitucional, n. ${ }^{\circ}$ 28, pp. 347-394. 
territorial o en lo relativo a la protección de los derechos fundamentales ${ }^{21}$. No estaría de más, se me ocurre, valorar como un ítem positivo que la persona candidata hubiese tenido un compromiso activo - y por tanto político ${ }^{22}$ - en cualquier ámbito relacionado con la efectiva garantía de los derechos de la ciudadanía. Como tampoco estaría de menos, más bien estaría de menos en el caso que no se acreditase, que las personas propuestas demostrasen tener conocimientos en materia de igualdad de género y de cómo han aplicado dicho criterio en su trayectoria como juristas ${ }^{23}$.

$\mathrm{Si}$, como bien señala el artículo $4 \mathrm{LOIMH}$, «la igualdad de trato y de oportunidades entre mujeres y hombres es un principio informador del ordenamiento jurídico y, como tal, se integrará y observará en la interpretación y aplicación de las normas jurídicas», no sería descabellado controlar que los/as miembros/as del TC sean conscientes de esa exigencia y que así la hayan aplicado transversalmente en sus dilatadas trayectorias. En este sentido, empezamos a encontrarnos por ejemplo decisiones judiciales que van delimitando qué debe entenderse por dimensión de género en la interpretación y aplicación del Derecho ${ }^{24}$, al margen de que la

${ }^{21}$ En esta línea habría que recordar lo que con tanta lucidez plantea G. Zagrebelsky: «es importante que los llamados al cargo de juez constitucional tengan una fuerte personalidad y una trayectoria profesional digna que merezca ser reivindicada y defendida. Las medias figuras, los tibios, los Nicodemos, que manifiestan sus ideas con claridad, constituyen un grupo de los que siempre están dispuestos, como se dice, a "cambiar de chaqueta” según sople el viento (...) Son precisamente ellos, las personas no comprometidas, las que al no ser fieles a sus principios cambian con mayor facilidad de fidelidades». Zagrebelsky, G. (2003), Principios y votos. El Tribunal Constitucional y la política. Trotta, Madrid, pp. 58-59

22 Aunque soy consciente de que también sería discutible la posibilidad de que un magistrado o una magistrada del TC esté o y haya estado afiliado a un partido político. La doctrina está dividida al respecto y me inclino por pensar que no necesariamente la simple afiliación a un partido debería ser un obstáculo para formar parte del órgano. Cuestión distinta es que hubiese desempeñado algún tipo de responsabilidad pública o cargo representativo.

${ }^{23}$ La recomendación $n . .^{\circ} 25$ del Comité CEDAW, convención que fue ratificada por España en 1984, aclara qué debe entenderse por dicha perspectiva: «El género se define como los significados sociales que se confieren a las diferencias biológicas entre los sexos. Es un producto ideológico y cultural aunque también se reproduce en el ámbito de las prácticas físicas; a su vez, influye en los resultados de tales prácticas. Afecta a la distribución de los recursos, la riqueza, el trabajo, la adopción de decisiones y el poder político, y el disfrute de los derechos dentro de la familia y en la vida pública. Pese a las variantes que existen según las culturas y la época, las relaciones de género en todo el mundo entrañan una asimetría de poder entre el hombre y la mujer como característica profunda. Asípues, el género produce estratos sociales y, en ese sentido, se asemeja a otras fuentes de estratos como la raza, la clase, la etnicidad, la sexualidad y la edad. Nos ayuda a comprender la estructura social de la identidad de las personas según su género y la estructura desigual del poder vinculada a la relación entre los sexos».

${ }^{24}$ Sirva como ejemplo la «pionera» en este sentido la Sentencia de la Sala de lo Social del Tribunal Superior de Justicia de Canaria, de 7 de marzo de 2017, en la que, ante una petición de una pensión de viudedad por una mujer que había sido víctima de violencia de género, se señala expresamente que «La interpretación social del Derecho con perspectiva de género exige la contextualización y la actuación conforme al principio pro persona, que se configura en este ámbito como un criterio hermenéutico que obliga a los órganos jurisdiccionales a adoptar interpretaciones jurídicas que garanticen la mayor protección de los derechos humanos, en especial los de las víctimas. Los estereotipos de género son la base 
formación en esta materia continúe siendo un deseo más que una realidad en el ámbito jurídico ${ }^{25}$.

Este perfil sería el que en la práctica debería ser sometido a un riguroso control en las comparecencias parlamentarias que se han previsto en el caso de las candidaturas propuestas por el Congreso y el Senado. Algo que en la práctica está lejos de ser efectivo ya que las mismas se han convertido en una mera formalidad que solo sirve para revestir de una cierta legitimidad lo que los dos partidos mayoritarios han pactado con carácter previo.

\subsection{El método de elección}

La regulación constitucional del procedimiento de selección de la magistratura constitucional es escueta "pero con una apreciable densidad normativa, sin que pueda ser tachada de reglamentista, y que resulta homologable a otras Constituciones de nuestro entorno» ${ }^{26}$. Los problemas en la práctica no se han planteado tanto por las reglas establecidas sino más bien por el uso que de ellas han hecho los partidos políticos, ya que estos las han manipulado para repartirse cuotas de poder, lo cual ha repercutido en una doble percepción en la opinión pública: $1 .^{a}$ ) los/as magistrados/as no actúan de manera independiente, sino condicionadas por sus «servidumbres» políticas; $2 .^{a}$ ) el TC actúa en bloques — conservador/progresista ${ }^{27}$ — de manera que

de la discriminación contra las mujeres. Su presencia en los sistemas de justicia tiene consecuencias perjudiciales para los derechos de las mujeres, particularmente para las víctimas y supervivientes de diferentes formas de violencia, pudiendo impedir el acceso a una tutela judicial efectiva. Los estereotipos de género han de ser erradicados en la interpretación y aplicación judicial.» Un ejemplo de este creciente interés es la recientemente presentada Guía práctica para la Abogacía: enfoque de género en la actuación letrada, de la que son autoras María Martín González y Elena Ocejo Álvarez (http://www.abogacia.es/ wp-content/uploads/2017/12/GUIA-ENFOQUE-DE-GENERO.pdf, consultada: 20/12/17). Sobre la aplicación de los presupuestos y metodología feminista al razonamiento jurídico véase CosTA, M. (2016), Feminismos jurídicos, Didot, Buenos Aires.

25 Véase por ejemplo cómo en el recientemente aprobado Pacto de Estado en materia de violencia de género, incorpora de manera expresa entre sus medidas: «Introducir más temas de Derecho Antidiscriminatorio, incluyendo la perspectiva de género y la transversalidad, en las oposiciones a judicatura, Escuela Judicial, y formación continua anual, impartida por el Consejo General del Poder Judicial, pasando esta materia a ser obligatoria y evaluable. Asimismo introducir pruebas específicas en violencia de género, como requisito para concursar a órganos judiciales especializados»; «Proponer al Consejo General de la Abogacía Española que impulse para todos sus colegiados/as y en todos los Colegios de Abogados de España, la homogeneización de una formación de calidad en Derecho Antidiscriminatorio, que incluya la perspectiva de género y la transversalidad.» Boletín Oficial de las Cortes Generales, Congreso de los Diputados, Serie D, n. ${ }^{\circ} 199,3$ de agosto de 2017.

26 García Roca, J. (2012), cit. , p. 4.

27 Díez Revorio, F. J. (2011), «Encuesta sobre la renovación del Tribunal Constitucional», cit., P. 22. En un sentido similar, I. Sánchez Cuenca, el cual lleva a cabo un exhaustivo análisis del sesgo ideológico de los magistrados que hasta la fecha del estudio formaron parte del TC. SÁNCHEZ CuENTA, I. (2012), «Los retrasos y los sesgos de la composición del Tribunal Constitucional», en Informe sobre la democracia en España 2011, Fundación Alternativas, Madrid, pp. 285 ss. 
sus decisiones dependen finalmente del peso numérico que tenga uno u otro. De esta manera se ha producido una «perversión» de la lógica del sistema establecido constitucionalmente: lejos de evitar «la tentación de llevar partidarios a las instituciones», en la práctica lo que se produce es un reparto de cuotas de $\operatorname{poder}^{28}$. Esa perversión del sistema se ve amplificada por los reiterados retrasos de las dos Cámaras legislativas en las renovaciones ${ }^{29}$, lo cual revela una escasa preocupación de los grupos parlamentarios por cumplir unos plazos ya que la continuidad del funcionamiento del órgano está garantizada.

La reforma de la Ley Orgánica 2/1979, de 3 de octubre, del Tribunal Constitucional (en adelante, LOTC) llevada a cabo por la LO 6/2007, de 24 de mayo ${ }^{30}$, dispuso en el segundo párrafo del art. 16.1 que los/as magistrados/as propuestos/ as por el Senado sean elegidos/as entre las candidaturas presentados por las Asambleas Legislativas de las Comunidades Autónomas en los términos que determine el Reglamento de la Cámara. Se trata de una reforma que había sido demandada por buena parte de la doctrina ya que con ella se buscaba un mayor ajuste con la estructura descentralizada del Estado autonómico ${ }^{31}$, y que por otra parte ya

28 «La exigencia de mayorías reforzadas ha dado lugar a que, en vez de esforzarse los grupos parlamentarios concernidos en seleccionar candidatos susceptibles de recibir por sus cualidades profesionales e idoneidad personal el apoyo de todos los miembros o, al menos, de los tres quintos de la cámara llamada a realizar la designación, se ha extendido la práctica de las llamadas cuotas. Es decir, de la distribución de los puestos a cubrir de tal modo que, en función de la relación de fuerza, o sea del número de diputados o de senadores de cada uno de los principales grupos, se reservan la elección de un número determinado de vocales o magistrados. A esta práctica — que, por sí sola, no sería decisiva para desnaturalizar el sistema - se le añaden, sin embargo, unos rasgos que sí producen ese efecto. Me refiero a que, a menudo, esas cuotas son ciegas o incondicionadas porque los grupos concernidos no discuten las propuestas de sus adversarios sino que se limitan a aceptarlas a condición de que sean aceptadas las suyas. En este caso, sin perjuicio de que los elegidos deban ser juristas de reconocida competencia con los años de ejercicio requeridos o miembros de la Carrera Judicial, el procedimiento de selección les marca con una señal de proximidad a la formación que les propone, con lo cual se abre un flanco a la crítica que denuncia la politización del nombramiento y a sus actuaciones futuras en el seno del órgano constitucional que, inevitablemente, serán presentadas y valoradas no en función de los argumentos jurídicos que las sustenten, sino desde la perspectiva ofrecida por ese sesgo de partida». LuCAs MuriLlo De LA Cueva, P. (2010), cit., p. 134.

${ }_{29}$ Un análisis de los sucesivos retrasos producidos en la renovación de los magistrados puede verse en SÁnChez Cuenca, I. (2012), cit., pp. 290-292.

30 Debemos recordar que «esta regla fue aprobada sin el necesario consenso constitucional, ya que se trata de una ley que integra el bloque de la constitucionalidad, un error del que deberían extraerse futuras lecciones, y esta preterición de la minoría mayoritaria generó un poco edificante conflicto en su primer uso, alejándose de la finalidad pretendida por la norma». GARCía RoCA, J. (2012), cit., p. 5. Esta falta de consenso ha sido subrayada como un factor determinante en la erosión del prestigio del TC. Fernández Miranda, A. (2011), cit. , p. 31. Sobre esta reforma véase Carrillo, M. (coord.), (2008), Hacia una nueva jurisdicción constitucional: estudios sobre la Ley 6/2007, de 24 de mayo de reforma de la LOTC. Valencia, Tirant lo Blanch.

31 Esta reforma ha sido objeto de numerosas críticas entra la doctrina. Así, hay opiniones como la de L. de Aguiar de Luque que considera que: «la reforma de la LOTC ni potencia realmente la dimensión territorial del Senado... ni sirve para dotar de proyección autonómica en la composición del Tribunal... 
habían de alguna manera «adelantado» las reformas estatutarias realizadas en los años 2006 y $2007^{32}$.

El Grupo Popular recurrió esta modificación y el TC la consideró constitucional en su sentencia 49/2008, de 9 de abril ${ }^{33}$. Un fallo que fue contradicho por varios votos particulares y que fue contestado por parte de la doctrina ${ }^{34}$. Entre otras cosas, se insistió en como la reforma eliminaba la libertad del Senado para seleccionar, por sí mismo, los candidatos del art. 159.2 CE, cuando la integración de la estructura territorial del Estado estaba ya «prevista y querida por la Constitución exactamente y en la medida que establece en sus arts. 69 y 159.1» (voto particular de J. Delgado Barrio). En todo caso, entiendo que aunque se limitan las competencias del Senado, no se desapodera totalmente a la cámara de la función constitucionalmente asignada.

También fue recurrida la reforma realizada en el art. 184.7 del Reglamento del Senado, con fecha de 1 de noviembre de $2007^{35}$. El recurso fue resuelto por la STC

En contra (...) proyecta una imagen de representatividad de intereses territoriales por los magistrados así nombrados que creo que no contribuye a mejorar nuestro sistema de jurisdicción constitucional a la par que distorsiona en el imaginario colectivo el papel del Tribunal Constitucional en nuestro régimen constitucional». Mucho más tajante se muestra A. Fernández Miranda: «la partidocracia que nos gobierna convierte este procedimiento en cínicamente retardatario e inútil». AGUIAR DE LUQUe, L. y FERNÁNDEZ MIRANDA, A. (2011), «Encuesta sobre la renovación del Tribunal Constitucional», cit., p. 59 y p. 63. Con carácter previo a la reforma, R. Blanco Valdés ya había advertido críticamente contra esta pretensión, afirmando que «el Tribunal Constitucional no está formado por representaciones — territoriales, institucionales u orgánicas- de nadie». BLANCO VALDÉZ, R. (1999), «La política y el Derecho: veinte años de justicia constitucional y democracia en España (apuntes para un balance)», Teoría y Realidad constitucional, n. ${ }^{\circ} 4,2 .^{\circ}$ semestre, p. 272. Otros constitucionalistas, sin embargo, habían reclamado dicha participación. Por ejemplo, García Roca, J. y Rodríguez Bereijo, (1999), «Cuestionario sobre la reforma de la LOTC», cit., pp. 20 y 30.

${ }^{32}$ El art. 180 de la LO 6/2006, de 19 de julio, de reforma del Estatuto de autonomía de Cataluña prevé la participación de la Generalitat «en los procesos de designación de Magistrados del Tribunal Constitucional y de miembros del Consejo General del Poder Judicial, en los términos que dispongan las leyes o, en su caso, el ordenamiento parlamentario». No hacen referencia expresa al TC, sino que se refieren solo a la participación de las CCAA en los procesos de designación de los órganos constitucionales los arts. 224 de la LO 2/2007, de 19 de marzo, de reforma del Estatuto de autonomía para Andalucía; 89.4 de la LO 5/2007, de 20 de abril, de reforma del Estatuto de autonomía de Aragón, y 58.2.d de la LO 14/2007, de 30 de noviembre, de reforma del Estatuto de Autonomía de Castilla y León.

${ }^{33}$ Un análisis crítico de las sentencias del TC que resolvieron los recursos de inconstitucionalidad planteados contra la reforma de la LOTC y la posterior del Reglamento del Senado puede verse en SÁNChez Barrilao, J.F. (2009) «La participación de las Comunidades Autónomas en la elección por el Senado de los magistrados constitucionales», Teoría y Realidad constitucional, n. ${ }^{\circ} 23$, pp. 387-424; y en Rodríguez-Patrón, P. (2010), «El Tribunal Constitucional ante la reciente reforma de los artículos 16 de su Ley Orgánica y 184 del Reglamento del Senado», Revista de Derecho Político, n . ${ }^{77}$, enero-abril, pp. 107-140.

34 URÍAS, J. (2010), «El Tribunal Constitucional ante la participación autonómica en el nombramiento de sus miembros», Revista de Estudios Autonómicos y Federales, n. ${ }^{\circ}$ 10, abril , pp. 207-244.

${ }^{35}$ Mediante la reforma del Reglamento del Senado se «salva» la objeción planteada en el recurso de inconstitucionalidad contra la reforma de la LOTC en el sentido de que sustraía al Senado de una 
$101 / 2008$, de 24 de julio, en un fallo también controvertido ya que varios votos particulares volvieron a discrepar de la decisión mayoritaria ${ }^{36}$. Todo ello nos muestra cómo en una cuestión tan esencial cómo la misma designación de los magistrados y las magistradas del TC se ha partido de la falta de acuerdo entre las principales fuerzas políticas, lo cual condenaba de alguna manera el modelo al uso partidista que luego se ha venido haciendo de él. Las dos sentencias comentadas han de ser interpretadas de forma conjunta ya que, en definitiva, lo que hace el TC es salvar la constitucionalidad de la reforma mediante una interpretación del art. 16.1 LOTC que lo considera como una norma abierta a distintas posibilidades de regulación por parte del Reglamento del Senado ${ }^{37}$. Ello llevaría a que en determinadas ocasiones pudiera prescindirse de las propuestas autonómicas con tal de garantizar que el Senado cumpliese con la función constitucionalmente asignada. Esa es la interpretación que el TC le acaba dando a la expresión «candidaturas suficientes» contenida en el nuevo artículo del RS, la cual por lo tanto no ha de entenderse limitada a una cuestión numérica sino que se amplía a la valoración que el Senado puede hacer sobre la idoneidad de las candidaturas ${ }^{38}$.

La reforma llevada a cabo en 2007 también introdujo la obligación de que las personas candidatas propuestas por el Congreso y por el Senado comparezcan ante las correspondientes Comisiones en los términos que dispongan los respectivos Reglamentos (art. 16.2). El objetivo de esta comparecencia es comprobar que las candidaturas cumplen los requisitos constitucionales y que dicho control se realice con las suficientes garantías de transparencia y publicidad. Sin embargo, en la práctica los partidos políticos han convertido este trámite en una mera formalidad, en la que

atribución constitucional. En la STC 49/2008 ya se sostuvo que «el tenor literal del art. 16.1 de la LOTC permite que el Reglamento del Senado pueda, entre otras fórmulas, prever, incluso, mecanismos que hagan posible que sea la propia Cámara la que proponga candidatos a Magistrados del Tribunal Constitucional en el supuesto excepcional de que el sistema de elección de dichos Magistrados previsto con carácter general no culmine con esta elección, garantizando así que la Cámara Alta cumpla con la obligación constitucional».

36 «La STC 101/2008 (FJ 9 y 10) estira el concepto de "candidaturas suficientes" del artículo 184.7 b) RS, de claro significado numérico, hasta hacerlo coincidir con el de candidaturas merecedoras de "la confianza institucional del Senado", de modo que la "insuprimible" libertad institucional de la Cámara le permitirá no aceptar los candidatos propuestos por las Asambleas autonómicas y designar en su lugar otros propuestos por los Grupos Parlamentarios senatoriales. Así, mediante una interpretación conforme, opuesta a un "un rígido entendimiento" del precepto reglamentario fundado en su "presunto tenor literal", y desechando igualmente la "voluntas legislatoris, derivada de los trabajos parlamentarios", el TC salva la inconstitucionalidad de la norma impugnada.» PUNSET BLANCO, R. (2011), «Encuesta sobre la renovación del Tribunal Constitucional», cit., p. 67.

37 Sobre las «trampas de la interpretación conforme» véase ToRres MUro, I., (2008), «La reforma de la LOTC y del Reglamento del Senado, puesta a prueba (SSTC 49/2008, de 9 de abril y 101/2008, de 24 de julio)», Revista General de Derecho Constitucional, n. ${ }^{\circ}$ 6, p. 19.

${ }^{38}$ De esta manera, «el TC ha configurado una válvula de seguridad. Si para ello ha tenido que dar alguna patada a nuestro maltratado castellano y, lo que es más grave, obviar lo que parecía ser la clarísima voluntad del legislador, cabe preguntarse si no ha sido un precio muy bajo el que ha tenido que pagar». Torres MURo, I. (2008), cit., p. 20. 
incluso los representantes de los grupos parlamentarios renuncian a hacer preguntas, y que simplemente sirve para hacer más largo y complejo el proceso de nombrar a quienes han sido objeto de negociación previa entre los partidos mayoritarios.

También concreta la LOTC que antes de los cuatro meses previos a la fecha de la expiración de los nombramientos, el Presidente del Tribunal solicitará de los Presidentes de los órganos que han de hacer las propuestas para la designación de los nuevos/as Magistrados/as, que inicien el procedimiento para ello (art. 17.1). El objetivo de esta previsión, que no es otro que el inicio sin dilaciones del procedimiento de designación, ha quedado desfigurado en la práctica gracias a la práctica perversa de los partidos.

\subsection{El retraso en las renovaciones de los/as magistrados/as}

Sin duda, uno de los mayores problemas a los que ha tenido que enfrentarse la jurisdicción constitucional en nuestro país han sido los retrasos en la renovación de los/as Magistrados/as por parte del Congreso y del Senado ${ }^{39}:$ «Los partidos tienden a acometer la renovación en el momento políticamente más oportuno para sus intereses, una primera irregularidad, así como a hacer una $<<$ cesta institucional $>>$ con las renovaciones de varios órganos, de entre los que deben ser elegidos, muy diferentes entre sí en su naturaleza y funciones, un segundo defecto no menos grave. Un tercero consiste en el fenómeno que llamamos <<lotización $>>$ (lottizzazione) y que consiste en desnaturalizar la lógica de las mayorías cualificadas, basadas en acuerdos, transformándolas en cuotas y devaluando su sentido jurídico» ${ }^{40}$.

Con respecto a la renovación de los magistrados, el art. 159.3 CE deja bien clara la regla a seguir: «Los miembros del Tribunal Constitucional serán designados por un período de nueve años y se renovarán por terceras partes cada tres ${ }^{41}$. A dicha

39 Un análisis detallado de las renovaciones acaecidas hasta 2012 puede verse en BorRAJo INIESTA, I. (2013), «Renovarse o morir: el ritmo de las renovaciones del Tribunal constitucional español», Revista General de Derecho Constitucional, n. ${ }^{\circ} 16$, pp. 9-40. La situación más extrema en cuanto a las dilaciones en la renovación de los miembros del TC dio lugar en 2007 a la prórroga del mandato como presidenta de la magistrada Emilia Casas, lo cual provocó una sucesión de irregularidades censuradas unánimemente por la doctrina: «el Tribunal no debiera debido de actuar con "regularidad" convalidando así una situación "irregular". Era su ocasión para hacer valer, por fin, su enérgico desacuerdo con lo que estaba sucediendo y para defender su dignidad constitucional (...) En situación excepcional lo que cabe es la Presidencia y la Vicepresidencia de edad (arts. 6.2 y 7.3)». Fernández MirandA, A. (2011), cit., pp. 35-36.

${ }^{40}$ García Roca, J., (2010), cit., p. 28.

${ }^{41}$ Ignacio Borrajo distingue tres interpretaciones de la fórmula constitucional, de acuerdo con la experiencia de los primeros 30 años de TC: «En las primeras renovaciones, el Tribunal siguió una interpretación idealista, que hizo primar la renovación por tercios aferrándose al mes fundacional, febrero. En una segunda fase, los reiterados retrasos que se venían produciendo en las renovaciones llevaron al Tribunal a cambiar su interpretación, procurando asegurar que los mandatos de los magistrados no durasen menos de los nueve años que dispone la Constitución. Finalmente, no puede dejar de observar- 
previsión habría que sumar la contenida en la Disposición Transitoria 9. ${ }^{a} \mathrm{CE}$, la cual ha de entenderse en vigor de manera permanente ${ }^{42}$.

El art. 17.2 LOTC contiene una previsión que ha sido una permanente fuente de conflictos: hasta que tomen posesión los nuevos miembros, los magistrados salientes continuarán en el ejercicio de sus funciones ${ }^{43}$. El problema es que esta prórroga se ha convertido en la regla general, lo cual ha pervertido en la práctica su fin principal ${ }^{44}$.

El art. 16.3 prevé que si el mandato de tres años para el que fueron designados como Presidente y Vicepresidente no coincidiera con la renovación del TC, quedará prorrogado para que finalice en el momento en que dicha renovación se produzca y tomen posesión los nuevos Magistrados. Esta previsión, introducida en 2007, no hizo sino contemplar la prorrogatio que de hecho venía dándose en la práctica ${ }^{45}$. En la STC 47/2008, el TC dejó claro que «la finalidad última de la reforma es la de garantizar que la elección de la Presidencia se produzca tras la renovación parcial del Tribunal y, por lo tanto, con la participación de nuevos magistrados». A pesar de la polémica generada, y de la contestación de este fallo en varios votos particulares, no entiendo que deba considerarse inconstitucional.

Mientras que la limitación del art. 16.4 LOTC, consistente en que ningún Magistrado podrá ser propuesto al Rey para otro período inmediato, salvo que hubiera ocupado el cargo por un plazo no superior a tres años, no ha generado polémica, la del apartado $5 .^{\circ}$ de dicho artículo, dirigida a solventar las disfunciones

se que existe una tercera interpretación posible, que pone el acento en salvaguardar el ritmo institucional del Tribunal procurando su renovación cada tres años». Borrajo InIESTA, I. (2013), cit., p. 40.

42 Borrajo Iniesta, I. (2013), cit., pp. 4-5.

43 Debemos recordar cómo la renuncia planteada por el magistrado Enrique López el 2 de junio de 2014 introdujo una excepción a la prórroga del art. 17.2 LOTC. El magistrado presentó su dimisión como consecuencia de los hechos que acontecieron el 1 de junio de 2014 y por los que acabaría siendo considerado culpable de un delito contra la seguridad vial (sentencia n. ${ }^{\circ} 45 / 2014$, de 14 de junio, dictada por el Juzgado de Instrucción n. ${ }^{\circ} 31$ de Madrid). El Real Decreto 588/2014, de 8 de julio, por el que se declaró el cese del magistrado, indicaba expresamente que el mismo cesaba en sus funciones «a partir de la toma de posesión de quien hubiere de sucederle». Al día siguiente se publicó en el $B O E$ una corrección de errores en la que se puntualizaba que el cese tenía efectos «desde el 6 de junio de 2014, fecha de efectividad del Decreto del Presidente del Tribunal Constitucional por el que se aceptó su renuncia...» De esta manera, se dio entrada a «una nueva causa para que el Presidente del Tribunal Constitucional pueda apartarse del contenido del 17.2 de la LOTC, al momento de decretar la aceptación de la renuncia. Esta causa estará inspirada en razones cercanas al terreno de la protección de la imagen institucional o auctoritas del Tribunal». Estrada Marún, J.A. (2015), «La designación de magistrados del Tribunal Constitucional por el gobierno. Apuntes con motivo del nombramiento efectuado en 2014», Revista de Estudios Políticos, n. ${ }^{\circ} 170$, octubre-diciembre, pp. 247-276.

44 Es decir, «la prorrogatio se ha erigido en una norma de cobertura para un claro rodeo a la ley, un verdadero fraude constitucional, que redunda en el incumplimiento de los plazos de renovación». GARCía Roca, J., (2010), cit. , p. 8.

45 Véanse por ejemplo las opiniones de Díez Revorio, F. y Santamaria Pastor, J.A., (2011), pp. 73-74.

(C) UNED. Revista de Derecho Politico

N.o 101, enero-abril 2018, págs 741-774 
que de hecho han supuesto los retrasos en las renovaciones del TC, ha sido especialmente controvertida ${ }^{46}$. El objetivo de esta reforma era evitar que en lo sucesivo las renovaciones parciales del TC correspondientes al Congreso y al Senado coincidieran en el tiempo, infringiéndose así la regla del 159.3 CE. A su vez, se pretendía evitar que una mayoría política pudiera condicionar la composición mayoritaria del TC. La reforma, llevada a cabo por la LO 8/2010, de 4 de noviembre, es claramente inconstitucional en cuanto que el art. 159.3 CE deja claro que el mandato de los/ as magistrados/as ha de ser de 9 años ${ }^{47}$. Además, «esta medida asienta definitivamente como inevitable la prórroga indefinida del mandato, transforma el ser en deber ser, los retratos y dilaciones estructurales en regla, recortando indebidamente el Mandato de los jueces constitucionales siguientes, en vez de impedir los abu$\operatorname{sos} »^{48}$. Es decir, como de manera unánime ha subrayado la doctrina, con ella se remediaba una infracción constitucional —el retraso en los plazos de renovación de los magistrados - a través de la infracción que supone contradecir las previsiones constitucionales. Y no es solo que la CE no deje margen al legislador para regular la duración del mandato de los magistrados, sino que la reforma posibilita que los órganos encargados de las renovaciones puedan administrar los tiempos en función de su conveniencia política ${ }^{49}$.

${ }^{46}$ Así las cosas, una vez que los dos principales grupos políticos de las Cortes Generales (el Grupo Socialista y el Grupo Popular) — sin cuyo concurso no es posible consensuar en las Cámaras los nombramientos de nuevos magistrados del TC_ pactaron a finales de septiembre de 2010 desbloquear la renovación pendiente en el Senado y llevar a cabo la correspondiente al Congreso en su debido momento, hubieron de acordar asimismo la introducción de un mecanismo que, pese a la coincidencia o proximidad en el tiempo de ambas renovaciones, impidiese que también en lo sucesivo la propuesta de nuevos magistrados del TC por ambas Cámaras se volviese a solapar(...) Para no demorar la renovación pendiente en el Senado y poder llevar también a cabo la correspondiente al Congreso antes de que finalizara 2010, se acordó incorporar la reforma de la LOTC a través de una enmienda de adición a alguna Ley Orgánica que en aquel momento se hallase en tramitación en las Cortes, en lugar de tramitar de forma independiente una iniciativa legislativa específica, lo que sin duda, hubiese demorado todo el proceso durante algunos meses más. Se decidió aprovechar a tal efecto la reforma de la Ley Orgánica del Régimen Electoral General que se estaba tramitando y que tenía por objeto modificar el modelo de papeleta electoral que se utiliza en las elecciones al Senado. De este modo, la reforma de la LOTC se pudo tramitar de manera expeditiva, en menos de un mes». BACigalupo, M. (2012), «La patología institucional, sin fin y elevada a categoría legal. La polémica reforma del período de nombramiento de los magistrados del Tribunal Constitucional, provocada por los reiterados y prolongados retrasos de sus renovaciones», Informe sobre la democracia en España 2011, Fundación Alternativas, Madrid, pp. 270-271.

${ }^{47}$ En este sentido se pronuncian la mayoría de los juristas consultados en la «Encuesta sobre la renovación del Tribunal Constitucional», cit., pp. 80-86. Discrepa J.A. Santamaría Pastor, el cual considera que el plazo del art. 159.3 CE debe ser entendido como aplicable en situaciones normales de cese y renovación, no en las anormales de cese anticipado o prórroga del mandato por demora en la renovación (op. cit., p. 85).

${ }^{48}$ Garcia Roca, J. (2010), cit., p. 9.

49 Recoge las críticas que provocó la reforma Bacigalupo, M. , (2012), cit., pp. 273-274. Este mismo autor analiza también lo improbable que sería, pese a todas las dudas suscitadas, el plantea- 
La doctrina ha propuesto varias alternativas con el objetivo de evitar las dilaciones en los nombramientos ${ }^{50}$, aunque es mayoritaria la posición que mantiene que estamos ante una cuestión que no se puede resolver con medios jurídicos sino más bien con un mayor sentido institucional de los grupos parlamentarios ${ }^{51}$. Entre las muchas propuestas que se han hecho en los últimos años, cabe señalar por ejemplo la que sugiere que se entiendan automáticamente renovados para otro mandato a los/as magistrados/as salientes. Esta propuesta chocaría sin embargo con la limitación temporal que marca el art. 159.3 CE, por lo que sería necesaria una reforma constitucional, además que de hecho permitiría que algunos magistrados desempeñaran su cargo durante 18 años, lo cual parece un período excesivo. También cabría como solución que el TC fuese el encargado, pasado un determinado plazo, de enviar una propuesta al órgano encargado de la designación ${ }^{52}$. En todo caso, la solución más fácil sería derogar la prorrogatio prevista en el art. 17.2 LOTC y que tantos problemas está provocando en la práctica ${ }^{53}$.

No faltan propuestas más «radicales» y que exigirían en todo caso una reforma constitucional. Así, Javier García Roca propone, de manera subsidiaria en el caso de que la renovación continuara atascada, el nombramiento de los doce magistrados a la vez, cada nueve años ${ }^{54}$. Una propuesta que parte de una hipótesis tal vez demasiado optimista — «los partidos pueden estar tentados de esperar y detener el proceso de renovación si vislumbran una situación más favorable a sus intereses, según sus expectativas o predicciones electorales tres años más tarde, pero difícilmente podrán imaginar cómo estará su poder electoral nueve años después»- y que no oculta el coste

miento de un recurso de inconstitucionalidad contra dicha reforma (pp. 75-76). Como ha señalado Ignacio Borrajo, tras la reforma de 2010 las acusaciones a los grupos parlamentarios de manipular la composición del TC sería más graves ya que la reforma permite designar magistrados «con un mandato temporal variable, en función de criterios o intereses bastardos». BORRAJO INIESTA, I. (2013), cit., p. 53.

${ }_{50}$ Sigo las propuestas que recoge García Roca, J. (2010), cit., pp. 29-30.

${ }^{51}$ Véanse por ejemplo las opiniones de varios constitucionalistas en «Encuesta sobre la renovación del Tribunal Constitucional», cit., pp. 75-80.

52 En Alemania, después de dos meses de retraso en la renovación del TC, la Cámara a la que corresponda hacer la renovación podrá pedirle al mismo Tribunal la sugerencia, no vinculante, de tres candidatos. SERVICIO DE ESTUDIOS, BIBLIOTECA Y DOCUMENTACIÓN DEL TRIBUNAL CONSTITUCIONAL, (2001), «Modelos de renovación personal de Tribunales Constitucionales, Revista Española de Derecho Constitucional, n. ${ }^{\circ} 61$, , pp. 223-224. Véase en este sentido la opinión de FernánDez Miranda, A. (2010), cit., p. 87.

53 Es la opinión que por ejemplo mantienen García Roca, J. —(2010), .cit., p. 30— o SantaMARÍA PASTOR, J.A. (2008), «La prorrogatio de los órganos constitucionales. Apuntes mínimos sobre un tema que no lo es», Revista Española de Derecho Constitucional, n. ${ }^{\circ}$ 84, pp. 11-26. Frente a la posición de estos autores, advierte de los riesgos de paralización del TC que conllevaría suprimir la prorrogatio, Aguiar De LuQue, L. (2009), «Una nueva reflexión sobre la prorrogatio de los órganos constitucionales. Una discrepancia y algunas puntualizaciones a J.A. Santamaría», Revista Española de Derecho Constitucional, n. ${ }^{\circ} 85$, pp. 83-98.

${ }^{54}$ García Roca, J. (2010), cit., p. 33. 
que podría suponer — «el riesgo de renovaciones tan bruscas de la jurisprudencia de la institución como en la composición del órgano» ${ }^{55}$.

La doctrina ha insistido en buscar herramientas que permitan superar la lógica del Estado de partidos en el TC como la consistente en la introducción de una renovación individual de los Magistrados, lo cual obligaría a llegar a un acuerdo y eliminaría la posibilidad del reparto de cuotas ${ }^{56}$.

\section{LA COMPOSICIÓN DEL TRIBUNAL CONSTITUCIONAL DESDE EL PUNTO DE VISTA DEL GÉNERO}

\subsection{La desequilibrada composición del Tribunal}

Llama la atención cómo entre los cientos de páginas que en la última década se han escrito en torno a la composición del TC, tal y como se ha reflejado de manera resumida en las páginas anteriores, apenas ninguna de ellas haya llamado la atención sobre la escasa presencia de mujeres en dicho órgano, cuando incluso se ha llegado a debatir por un sector de la doctrina cuestiones como la edad de sus miembros ${ }^{57}$. Debemos recordar que de un total de 64 personas hasta la fecha solo 6 mujeres - la última en incorporarse ha sido la catedrática M. ${ }^{a}$ Luisa Balaguer en marzo de 2017 han sido magistradas del TC y solo una, Emilia Casas, ha llegado a ser Presidenta. De estos datos tan apabullantes podríamos deducir que «ser hombre» es, sino un requi-

55 Parece evidente que la única manera de superar la perversión analizada sería introducir en el texto constitucional previsiones expresas, de manera que se regulase directamente la provisión de cargos si en un plazo prudente no se hubieran cubierto. Señala P. Lucas Murillo de la Cueva que «el método tendría que ser de tal naturaleza que no permitiera hacer cálculos anticipados sobre posibles beneficiarios de la operación» y propone el sorteo entre una relación a amplia de sujetos (magistrados eméritos del TC, magistrados y fiscales de Sala del Tribunal Supremo, abogados, catedráticos de Universidad, funcionarios de determinados cuerpos, etc.). Lucas Murillo De La Cueva, L. (2013), cit., p. 139.

56 En esta línea se ha llegado también a proponer, aunque con muchas dudas por parte de la doctrina, que el nombramiento de los magistrados fuera vitalicio, como sucede en el Tribunal Supremo norteamericano, o hasta su jubilación, como sucede en tribunales como nuestro Tribunal Supremo. DíEZ Revorio, F.J. (2011), cit., p. 49. Esta es la propuesta que por ejemplo realiza Susana García Couso, para la que sería conveniente que el art. 159.3 CE dispusiera lo siguiente: «Los miembros del TC cesarán el día que cumplan setenta años de edad o, en su caso, tras de haber terminado el mandato de nueve años en el ejercicio del cargo desde el día de la toma de posesión, debiéndose proceder a la designación de la vacante por el órgano al que por turno correspondiese». Además propone una fecha límite que evite la dilación en los nombramientos — tres meses_- de manera que si en ese plazo no se consigue la renovación intervendría el Rey en su papel de árbitro y moderador del funcionamiento regular de las instituciones (art. 56.1 CE). El Rey procedería a la designación «entre una terna de Magistrados de carrera con más de veinte años de ejercicio profesional presentados por el Consejo del Poder Judicial en Pleno en la forma que determine la Ley Orgánica del Poder Judicial.» García Couso, S. (2012), «Cómo superar la lógica del Estado de partidos en el Tribunal Constitucional: la reforma del artículo 159 CE», Teoría y Realidad constitucional, n. ${ }^{\circ} 29$, pp. 444-447

57 García Roca, J., cit. (2010), p. 14; García Couso, S. (2012), cit., pp. 454-455. 
sito que condiciona el acceso a nuestra más alta magistratura, sí un elemento que se tiene en cuenta al valorar la «reconocida competencia» que se exige a las personas candidatas. Algo que, por otra parte, continúa siendo a estas alturas del siglo Xxi lo dominante en la mayor parte de las instituciones y órganos cuyos titulares son nombrados no solo teniendo en cuenta de manera objetiva sus méritos y capacidades sino en procedimientos con un elevado grado de discrecionalidad. Y no hace falta, insistir en cómo ese margen de discrecionalidad política ha sido usado por nuestros representantes en relación al TC, tal como hemos explicado en las páginas anteriores, de tal manera que junto al fenómeno de la lotizazzione podríamos denunciar la evidente continuidad de «una cuota de representación masculina» ${ }^{58}$. Ahora bien, mientras que con respecto al primer fenómeno se ha suscitado una prácticamente unánime posición crítica de la doctrina, con respecto al segundo son pocas las voces que se han alzado para denunciar la infrarrepresentación femenina.

Este silencio se rompió con motivo de la renovación de cuatro magistrados que le correspondía realizar al Senado a principios de 2017. De un parte, la Red Feminista de Derecho Constitucional (en adelante, RFDC) hizo público un documento a finales de noviembre de 2016 en el que reclamaba que se hiciera efectivo el mandato legal de igualdad de mujeres y nombres en los nombramientos de la magistratura constitucional $^{59}$. En concreto, ante la inminente renovación de 4 magistrados por el Senado, se solicitaba a todos los partidos con representación en las Asambleas autonómicas y en el Senado: $1 .^{\circ}$ ) que las candidaturas que las Asambleas legislativas de las Comunidades Autónomas elevasen al Senado sólo propusieran mujeres. 2. ${ }^{\circ}$ ) Que el Senado propusiese sólo a mujeres para ocupar los cuatro puestos que debían cubrirse en 2017. De esta manera, indicaba el documento, «la composición del Tribunal Constitucional hasta la próxima renovación parcial en el año 2021 será de 9 magistrados y 3 magistradas. Una desproporción (75\%-25\%) que no alcanza ni siquiera a la mínima exigencia legal a pesar de ser menor de la existente desde el 2001 (87\%-17\%)».

En un documento más extenso que acompañaba al anterior ${ }^{60}$, la RFDC recordaba cómo en 2008 las Asambleas legislativas de las Comunidades Autónomas elevaron sus

58 «Ello no significa necesariamente que la perspectiva de género haya estado poco presente en las sentencias del Tribunal Constitucional. Pero da que pensar. Lo que indudablemente ponen de manifiesto los datos es que las decisiones buenas, malas o regulares, si las valoramos desde la perspectiva de de la potestad de juzgar con perspectiva de género, han sido tomadas mayoritariamente por varones, algunos de los cuales, obviamente, han podido aportar una visión feminista, o determinados juicios, pero sin integrar el propio término (femenino o feminista) con una connotación positiva o constructiva, dentro de esas mismas resoluciones. El único conocimiento claro del pensamiento feminista (que se identifica por el Tribunal como “ideología feminista”) se da en la STC 12/2008 (reiterada en la STC 13/2009), que resuelve el recurso contra las cuotas electorales». GómEZ FERNÁNDEZ, I. (2017), Una Constituyente feminista. ¿Cómo reformar la Constitución con perspectiva de género? Marcial Pons, Madrid, p. 135.

59 http://feministasconstitucional.org/wp-content/uploads/2016/11/Posici\%C3\%B3n_RFDC_ ante_la_renovaci\%C3\%B3n_parcial_del_TC.pdf (consultada: 20/03/17)

${ }^{60}$ http://feministasconstitucional.org/wp-content/uploads/2016/11/Documento_explicativo._La_ RFDC_ante_la_renovaci\%C3\%B3n_paracial_del_Tribunal_Constitucional.pdf (consultada:20/03/17) 
propuestas al Senado en 2008, proponiéndose un total de 22 candidaturas, de las que sólo 4 eran mujeres (el 18\% del total de propuestas). De entre estas propuestas autonómicas la Comisión de Nombramientos del Senado (compuesta entonces por 6 senadores y 1 senadora) acordó, con los votos favorables de PSOE y PP, proponer a tres personas: 2 hombres y una mujer. El cuarto candidato (hombre también), no incluido en la relación de propuestas de procedencia autonómica, fue propuesto directamente por el grupo parlamentario popular. Así, en el Pleno del Senado de 1 de diciembre de 2010, se aprobó la propuesta de la Comisión de Nombramientos para los cuatro puestos a cubrir en el Tribunal Constitucional: 3 hombres y una mujer. La siguiente renovación parcial le correspondía al Congreso, que en julio de 2012 acordó designar también a tres magistrados y una magistrada. La última renovación parcial correspondió al Consejo General del Poder Judicial y al Gobierno en junio de 2013. La totalidad de magistrados propuestos fueron varones, incluyendo un quinto designado por el Gobierno en julio de 2014 como consecuencia de la dimisión de uno de los dos magistrados anteriormente designados por éste. El resultado es que en el momento previo la renovación que ha tenido lugar en 2017, la composición del TC era de 10 magistrados y 2 magistradas. El mismo número de magistradas desde $2001^{61}$.

No se trata, como bien explica la REFDC, de una simple reivindicación política o meramente ideológica. Se trata de una exigencia que deriva de nuestro propio sistema jurídico, en el cual «la igualdad de trato y de oportunidades entre mujeres y hombres es un principio informador del ordenamiento jurídico y, como tal, se integrará y observará en la interpretación y aplicación de las normas jurídicas» (art. 4 LOIMH). Dicha Ley Orgánica, que persigue hacer efectivo el mandato constitucional de igualdad desde el punto de vista del género, establece como criterios generales de actuación de los poderes públicos el «compromiso con la efectividad del derecho constitucional de igualdad entre mujeres y hombres» (art. 14. 1) y «la participación equilibrada de mujeres y hombres en las candidaturas electorales y en la toma de decisiones» (art. 14.4). Además, el art. 16 insiste en que «los Poderes Públicos procurarán atender al principio de presencia equilibrada de mujeres y hombres en los nombramientos y designaciones de los cargos de responsabilidad que les correspondan» ${ }^{62}$. Un mandato que, pese al carácter soft del verbo «procurarán», ha sido ignorado reiteradamente en la renovación del TC.

${ }^{61}$ El documento evidencia algo que no por obvio no merece ser recordado: «Es posible que en los inicios de funcionamiento del Tribunal Constitucional, debido a las restricciones tanto formales como materiales impuestas a las mujeres en los ámbitos educativo y profesional, no fuera fácil encontrar candidatas que reuniesen dichos requisitos. Pero desde hace ya años y, sobre todo, en el momento actual esa circunstancia ha desaparecido y, por tanto, no es posible su invocación para justificar su anecdótica presencia en el citado órgano constitucional. Hay magistradas, fiscalas, profesoras de universidad, funcionarias públicas y abogadas en número más que suficiente, con más de quince años de ejercicio profesional y muy competentes para desempeñar el cargo de Magistradas del Tribunal Constitucional. Las hay en tanta cantidad como los hombres, aunque los escalafones máximos los ocupen ellos todavía mayoritariamente.»

${ }^{62} \mathrm{La}$ DA 1. ' de la LOIMH entiende por "presencia equilibrada», la presencia de mujeres y hombres de forma que, en el conjunto a que se refiera, las personas de cada sexo no superen el sesenta por ciento ni sean menos del cuarenta por ciento. 
El mandato de composición equilibrada en la renovación del TC podría atenderse, de acuerdo con la propuesta de la RFDC, siguiendo dos posibles interpretaciones. Una primera, más restrictiva respecto de la efectividad de la igualdad, «vendría referida a la aplicación de la exigencia de presencia equilibrada únicamente a la propuesta que corresponda a cada instancia proponente, de tal forma que la proporción de personas de cada sexo propuestas no sea inferior al cuarenta por ciento ni superior al sesenta por ciento». Una segunda interpretación, más favorable a la efectividad del principio de igualdad, «vendría referida a la aplicación de la exigencia de presencia equilibrada teniendo en cuenta la totalidad del Tribunal Constitucional para que la proporción de personas de cada sexo no fuese inferior ni superior a los porcentajes anteriormente indicados». Como bien deduce la RFDC, la aplicación simultánea de ambas interpretaciones es imposible en el momento actual, pues la opción por una de ellas supondría, en última instancia, la inaplicación de la otra.

El documento acaba haciendo un doble llamamiento, dado el carácter de la renovación que habría de ponerse en marcha a finales de 2016. De una parte, a las Asambleas autonómicas, que son las encargadas de proponer candidatas ${ }^{63}$. De otra, al Senado, que es el órgano encargado de recibir las propuestas y convalidarlas o no ${ }^{64}$.

En la misma línea que la RFDC, la Asociación de Mujeres Juezas de España (AMJE) publicó el 5 de diciembre de 2016 un Manifiesto titulado «Por un Tribunal

63 «Si la voluntad de los Parlamentos autonómicos es el simple acatamiento formal de los mandatos legales respecto de la composición equilibrada de mujeres y hombres, optarán por una interpretación restrictiva y las propuestas que eleven al Senado incluirán a una candidata y a un candidato (y eso sólo en el supuesto de que propongan el número máximo permitido de propuestas). Si la voluntad de los Parlamentos autonómicos, por el contrario, es la de la completa eficacia normativa de las leyes de igualdad, entonces optarán por una interpretación extensiva de dichos mandatos y las propuestas que eleven al Senado únicamente incluirán a candidatas.»

64 «Recibidas las propuestas por el Senado, es a éste a quien corresponde constitucionalmente la propuesta definitiva, aprobándola por mayoría de tres quintos, para cubrir los cuatro puestos en el Tribunal Constitucional. Quedará al descubierto su voluntad dependiendo del criterio por el que se decante para hacerlo. Así, si la voluntad del Senado es el simple acatamiento formal de los mandatos legales respecto de la composición equilibrada de mujeres y hombres, debería proponer a dos mujeres. Si resulta ser de esta manera, la composición del Tribunal Constitucional hasta la próxima renovación parcial en el año 2021 será de 10 magistrados y 2 magistradas. Una desproporción (83\%-17\%) que se ha mantenido constante desde 2001. Si el resto de instancias proponentes actúan con el mismo criterio en los futuros procesos de renovación y éstos se llevan a cabo en el plazo constitucionalmente establecido, en 2021 serán 4 las magistradas (40\%) y en 2022 serán 6 (50\%), consiguiéndose así la paridad en la composición del Tribunal Constitucional. Pero, claro, estamos presumiendo que se van a acatar los mandatos legales y, como ya hemos advertido más arriba, eso no ha ocurrido en ninguno de los procesos de renovación parcial del 6 Tribunal Constitucional que se han llevado a cabo desde 2007, año de aprobación y entrada en vigor de la Ley orgánica 3/2007 para la igualdad efectiva de hombres y mujeres. Si la voluntad del Senado es la de la completa eficacia normativa de la citada Ley para la igualdad efectiva de mujeres y hombres, entonces la propuesta debería hacerse exclusivamente de mujeres. De esta forma se alcanzaría ya en un solo proceso y en 2017 la composición equilibrada del Tribunal Constitucional, pues habría 7 magistrados y 5 magistradas. Estaríamos así mucho más cerca de la consecución de esa democracia avanzada que se proclama en el Preámbulo de la Constitución española de 1978.» 
Constitucional equilibrado» y lanzó una campaña para la recogida de firmas ${ }^{65}$. La AMJE, reiterando los argumentos legales comentados, pedía que las cuatro plazas a renovar con carácter inmediato fueran ocupadas por mujeres, ya que «el Tribunal Constitucional, debe ser un referente ejemplar de la pluralidad social, y especialmente en la aplicación real (no formal) del principio de igualdad, tanto en sus resoluciones, cómo en su composición paritaria de mujeres y hombres.»

\subsection{Las escasas referencias comparadas}

En el contexto europeo no encontramos ninguna previsión constitucional o legislativa dirigida a garantizar una composición paritaria de mujeres y hombres en los correspondientes Tribunales Constitucionales. Solo encontramos previsiones dirigidas a ese objetivo en el Constitucionalismo latinoamericano. Así, por ejemplo, en el artículo 434 de la Constitución de Ecuador de 2008 encontramos un mandato de tipo promocional mediante el que se establece que en la integración de la Corte Constitucional «se procurará la paridad entre hombres y mujeres» ${ }^{66}$. Este mandato se concreta en la Ley Orgánica de Garantías Jurisdiccionales y control constitucional, en cuyo art. 180.3 se insiste en dicho objetivo, "para lo cual, de existir dos candidaturas en iguales condiciones, se preferirá la candidatura de la mujer» ${ }^{67}$.

También encontramos la exigencia de composición paritaria en el llamado Tribunal constitucional plurinacional de Bolivia, sobre el que la misma Constitución de 2009 dispone que «estará integrado por Magistradas y Magistrados» (art. 197.I) Hay que tener en cuenta que en este caso también se prevé representación del «sistema indígena originario campesino». En este sentido la ley n. ${ }^{\circ} 27$, de 6 de julio, del Tribunal Constitucional plurinacional, prevé que «al menos dos Magistradas y Magistrados provendrán del sistema indígena originario campesino, por auto-identificación personal» (art. 13) La paridad de género se prevé de manera específica en relación a

${ }^{65}$ http://www.mujeresjuezas.es/?p=633\&print=pdf (consultada: $20 / 03 / 17$ )

66 En este caso, además, habría que tener en cuenta el peculiar proceso de designación de los miembros de la Corte, los cuales «se designarán por una comisión calificadora que estará integrada por dos personas nombradas por cada una de las funciones, Legislativa, Ejecutiva y de Transparencia y Control Social. La selección de los miembros se realizará de entre las candidaturas presentadas por las funciones anteriores, a través de un proceso de concurso público, con veeduría y posibilidad de impugnación ciudadana». La norma que regula el funcionamiento de la Corte, la Ley Orgánica de Garantías Jurisdiccionales y control Constitucional de 2009, no concreta el mandato de paridad y se limita a respetar el lenguaje inclusivo al hablar de «juezas» $\mathrm{y}$ «jueces» que componen la Corte.

${ }^{67}$ Merece la pena destacar cómo en este caso, tanto la Constitución como las leyes que desarrollan las previsiones relativas a la Corte Constitucional encontramos un lenguaje no sexista, de manera que aparecen nombrados tanto hombres como mujeres. Así, por ejemplo, el art. 433 de la Constitución, al indicar los requisitos para ser designado miembro de la Corte Constitucional, se empieza por el de «ser ecuatoriana o ecuatoriano y encontrarse en ejercicio de sus derechos políticos». En el mismo sentido, la Ley Orgánica de Garantías Jurisdiccionales y control constitucional se refiere a las juezas y a los jueces de la Corte (art. 171). 
la propuesta de postulantes que ha llevar a cabo la Asamblea Legislativa Plurinacional, la cual «por voto de dos tercios de sus miembros presentes, realizará la preselección de veintiocho postulantes, de los cuales la mitad serán mujeres, y remitirá la nómina de precalificados al Órgano Electoral Plurinacional» (art. 19).

En un contexto diverso encontramos las previsiones de la Constitución de Sudáfrica en cuyo capítulo 8, dedicado a los Tribunales y la Administración de Justicia, dentro del cual se regula la Corte Constitucional, se incluye un mandato muy genérico según el cual «la necesidad de que la judicatura refleje ampliamente la composición racial y de género de Sudáfrica debe considerarse cuando se nombra a los funcionarios judiciales.»

Finalmente, es de interés recordar, dado que se trata de un órgano que en cierta medida podemos equiparar al Tribunal Constitucional, lo que dispuso la Asamblea Parlamentaria del Consejo de Europa en su Recomendación 1649(2004), relativa a la propuesta de candidatos para el Tribunal Europeo de Derechos Humanos ${ }^{68}$. Entre diversos criterios a tener en cuenta, la Asamblea insiste en la necesidad del equilibrio de género en los procedimientos de selección de jueces y juezas. En concreto, recomienda a los Estados miembros que las listas de personas candidatas incluyan tanto hombres como mujeres. Esta Recomendación, junto con otras previsiones del Comité de ministros del Consejo de Europa relativas a la composición del TEDH han sido recordadas en la reciente sentencia del Tribunal Supremo 968/2017, de 31 de mayo de $2017^{69}$ :

«Las Líneas Maestras del Comité de Ministros se refieren a la igualdad de género como criterio adicional a los del artículo 21 (punto 10) y recogen (Línea Maestra 8, punto 34), conforme a la Recomendación 1649 (2004), la Resolución 1426 (2005) y las Resoluciones 1627 (2008) y 1841 (2011), y la opinión consultiva del Tribunal de 12 de febrero de 2008, la indicación de que "por regla general" las listas de candidatos deberían ("should", "devraient"; no "deberán”, como pretende la parte actora) incluir al menos un candidato de cada sexo, "salvo si los candidatos pertenecen al sexo infrarrepresentado en el Tribunal (menos de $40 \%$ de Jueces)...", supuesto en el que la lista «puede componerse sólo de personas de ese sexo».

\footnotetext{
${ }^{68}$ http://assembly.coe.int/nw/xml/XRef/Xref-XML2HTML-en.asp? fileid=17193\&lang=en (consultada: $15 / 12 / 17$ )

${ }^{69}$ La sentencia estimó el recurso contencioso administrativo planteado por la Asociación Jueces para la Democracia contra el acuerdo del Consejo de Ministros de 20 de enero de 2017 por el que se establecían pautas para la elaboración de una terna de candidatos para la elección del Juez Titular del TEDH. Entendían los recurrentes que el Acuerdo introducía una discriminación por razón de edad (art. $14 \mathrm{CE}$ ), al exigir como requisito para ser candidato la edad de 61 años. Además, se alega que el Acuerdo implicaría una discriminación indirecta por razón de género (STC 3/2007, de 15 de febrero), ya que, «aunque está formulada de un modo neutro, su efecto desfavorable incide de un modo particularmente significativo, en atención a su infra representación en el TEDH, en el grupo social integrado por mujeres juristas».
} 


\subsection{Una cuestión de paridad}

El debate en torno a la composición equilibrada del Tribunal Constitucional, que podríamos trasladar al resto de órganos e instituciones del Estado, nos remite a su vez al que genera el «principio de paridad». El concepto de democracia paritaria ha dado lugar en las últimas décadas a un permanente debate en torno a su significado y, sobre todo, en torno a sus consecuencias en nuestros sistemas constitucionales. Aunque han predominando las discusiones centradas en su dimensión más cuantitativa - la presencia de las mujeres en posiciones de poder y los instrumentos para hacerla efectiva-, no deberíamos olvidar que la paridad tiene también una dimensión cualitativa que nos remite a las raíces mismas de la democracia. Si efectivamente la igualdad es el principio jurídico y el valor ético que sustenta el sistema que mejor garantiza los derechos y libertades de los individuos, difícilmente el mismo merecerá el calificativo de democrático si la mitad femenina no goza de un estatuto de ciudadanía igual al de la mitad masculina. Es decir, si no participan en las mismas condiciones y con las mismas oportunidades en el ejercicio del poder. Por lo tanto, no es osada sino por el contrario obligada consecuencia afirmar que la democracia $o$ es paritaria 0 no es.

A la espera de que el principio de paridad se incorpore de manera expresa en una urgente y necesaria reforma constitucional ${ }^{70}$, no podemos negar a estas alturas que el mismo forma parte de las esencias del sistema y que, por lo tanto, ha de proyectarse en cualquier actuación de los poderes públicos y ha de presidir cualquier interpretación que hagamos de nuestro ordenamiento jurídico. Porque, insisto, estamos hablando nada más y nada menos que del derecho fundamental de las mujeres a acceder al espacio público, a participar en el ejercicio del poder y a formar parte de la definición de las políticas que nos afectan a todas y a todos. No se trata por tanto de una cuestión de cuotas, que supondría establecer una reserva de puestos para de esa forma corregir la desigualdad real, sino de partir del presupuesto de que la ciudadanía democrática está dividida en dos géneros, uno de los cuales ha estado durante siglos postergado en el espacio público ${ }^{71}$.

70 Sobre esta cuestión véanse ESQUEMBRE CERDÁ, M. «Las mujeres ante el cambio constitucional. Algunos apuntes desde una perspectiva feminista para una "reforma constituyente” de la Constitución Española», y Salazar Benítez, O. , «Género, poder y ciudadanía», ambos en Gómez HernáNDEZ, I. (ed.), (2017), Revisar el pacto constituyente en perspectiva de género, Cuadernos Manuel Giménez Abad, n. ${ }^{\circ}$, febrero, pp. $75-92$ y $58-74$.

${ }^{71}$ Tal y como se constató en la llamada Declaración de Atenas, adoptada en la primera Cumbre Europea Mujeres en el Poder», celebrada en la capital griega el 3 de noviembre de 1992, la cual partía de los siguientes reconocimientos: «PORQUE la democracia exige la paridad en la representación y en la administración de las naciones. PORQUE las mujeres constituyen la mitad de las inteligencias y de las capacidades potenciales de la humanidad y su infra-representación en los puestos de decisión constituye una pérdida para el conjunto de la sociedad. PORQUE una participación equilibrada de mujeres y hombres en la toma de decisiones puede generar ideas, valores y comportamientos diferentes, que vayan en la dirección de un mundo más justo y equilibrado tanto para las mujeres como para los hombres. PORQUE la infra-representación de las mujeres en los puestos de decisión impide asumir plenamente 
No serían aplicables por tanto a la propuesta que planteo en estas páginas las críticas que resaltarían la posible confusión que un sistema de cuotas podría plantear sobre la misma naturaleza del TC, al tratar de aplicarle un mecanismo corrector que en general se ha venido usando para órganos representativos o, en todo caso, de carácter estrictamente político. Es decir, como un mecanismo corrector que ha actuado siempre en el contexto de procedimientos electivos y por tanto en el marco de la lógica democrática de un sistema competitivo de partidos. Con independencia de que, como hemos analizado en las primeras páginas de este trabajo, la misma composición del TC o, mejor dicho, el uso que de la misma están haciendo los partidos, pone en cuestión su propia naturaleza, no estamos proponiendo aquí una mera corrección que obligue a la inclusión de candidatas mujeres en las propuestas que, recordemos, acaban realizando los partidos. Por supuesto, que los criterios meritocráticos, basados en su reconocida competencia y dilatada trayectoria, seguirían siendo los determinantes, pero siempre que partamos del presupuesto de que un órgano constitucional, legitimado democráticamente, ha de responder a cómo la sociedad se estructura desde el punto de vista del estatuto no tanto jurídico sino social y cultural de los individuos. Un estatuto que hoy por hoy continúa marcado por el género, el cual no es una categoría equiparable a ninguna otra circunstancia personal o social, por lo que de ninguna manera se plantearía lo que alguno podría reprochar como el peligro de la «pendiente deslizante»: «No se trata, pues, de una medida basada en los criterios de mayoría/minoría (como sucedería si se tomase en cuenta como elementos de diferenciación, por ejemplo, la raza o la edad), sino atendiendo a un criterio (el sexo) que de manera universal divide a toda sociedad en dos grupos porcentualmente equilibrados» (STC 12/2008). En este sentido, debemos tener presente cómo el art. 23.2 de la Carta de Derechos Fundamentales de la Unión Europea dispone que «el principio de igualdad no impide el mantenimiento o la adopción de medidas que ofrezcan ventajas concretas en favor del sexo menos representado.» Lo cual encaja a su vez con la interpretación que el propio TC ha hecho sobre la efectividad del art. 9.2 CE en materia de igualdad de género (STC 13/2009, de 19 de enero, FJ 10):

«En otros términos, "el art. 9.2 CE expresa la voluntad del constituyente de alcanzar no sólo la igualdad formal sino también la igualdad sustantiva, al ser consciente de que únicamente desde esa igualdad sustantiva es posible la realización efectiva del libre desarrollo de la personalidad; por ello el constituyente completa la vertiente negativa de proscripción de acciones discriminatorias con la positiva de favorecimiento de esa igualdad material" (STC 12/2008, FJ 4). El art. 9.2 CE, en definitiva, "encomienda al legislador la tarea de actualizar y materializar la

\footnotetext{
los intereses y las necesidades del conjunto de la sociedad. PROCLAMAMOS la necesidad de alcanzar un reparto equilibrado de los poderes públicos y políticos entre mujeres y hombres. REIVINDICAMOS la igualdad de participación de las mujeres y de los hombres en la toma de decisiones públicas y políticas. DESTACAMOS la necesidad de realizar modificaciones profundas en la estructura de los procesos de decisión con el fin de asegurar dicha igualdad.» (http://www.urv.cat/media/upload/arxius/igualtat/ JeanMonnet/2013/Lectura_recomendada_Declaracion_Atenas_1992.pdf, consultada: 15/12/17).
} 
efectividad de la igualdad que se proyecta, entre otras realidades, en el ámbito de la representación, correspondiendo a este Tribunal Constitucional la función de examinar si las decisiones adoptadas al respecto son acordes con el marco constitucional aquí definido. ... Del art. 9.2 CE, y de la interpretación sistemática del conjunto de preceptos constitucionales que inciden en este ámbito, deriva la justificación constitucional de que los cauces e instrumentos establecidos por el legislador faciliten la participación de todos los ciudadanos, removiendo, cuando sea preciso, los obstáculos de todo orden, tanto normativos como estrictamente fácticos, que la impidan o dificulten y promoviendo las condiciones garantizadoras de la igualdad de los ciudadanos»

No estoy planteando, por tanto, la introducción de cuotas de género en la selección de quienes componen el TC ${ }^{72}$ - algo que, por otra parte, y como he comentado previamente, se admite sin discusión en relación a las que de tipo territorial se aplican en la actualidad—-, sino que defiendo que la composición de cualquier órgano e institución del Estado ha de responder a los criterios de paridad para gozar de plena legitimidad democrática. Aunque las denominadas cuotas de género y la paridad persiguen un mismo objetivo — la redefinición del espacio público en términos igualitarios-, responden a una lógica distinta. Mientras que las primeras se articulan como medidas de acción afirmativa, que encontrarían amparo en el art. 9.2 CE, «la paridad no se limita a problematizar la posición de las mujeres dentro de la ciudadanía; más bien problematiza la construcción dicotómica de ésta en términos sexuados, convirtiendo, no sólo a las mujeres, sino también a los varones, a sus respectivos roles ciudadanos, en su foco de atención ${ }^{73}$. Al no tratarse de una cuota, no estaríamos hablando por tanto de una medida coyuntural ${ }^{74}$, que se agotaría una vez alcanzado el objetivo de igualdad propuesto, sino que estaríamos hablando de un componente estructural, y por tanto de carácter definitivo, de un órgano constitucional.

La paridad debería ser fundamento no solo de las instancias estrictamente representativas, en las que además el TC ha dejado bien claro que debe ser así (SSTC 12/2008 y 13/2009), sino de todas aquellas instituciones que impliquen ejercicio

72 Dos términos, cuotas y paridad, que con frecuencia se confunden. Véanse por ejemplo en este sentido los argumentos que el magistrado Rodríguez Zapata usa en su voto particular a la STC 12/2008, los cuales reitera en su voto también discrepante con la STC 13/2009. También se observa esta confusión en autores como Aranda Álvarez, E. (2013), Democracia paritaria. Un estudio crítico, CEPC, Madrid.

73 Rodríguez Ruiz, B. (2017), Género y Constitución. Mujeres y varones en el orden constitucional español, Juruá editores, Lisboa, p.144.

${ }^{74}$ Ese carácter temporal es que justifica constitucionalmente las denominadas acciones positivas: «Obviamente esta medida en concreto (como con carácter general todas las dirigidas a la promoción activa de un colectivo discriminado) sólo se justifica en la realidad de las circunstancias sociales del momento en que se adopta, de manera que su misma eficacia habrá de redundar en la progresiva desaparición del fundamento constitucional del que ahora disfruta. Se trata, en definitiva, de una medida sólo constitucionalmente aceptable en tanto que coyuntural, en cuanto responde a la apreciación por el legislador de una situación determinada» (STC 13/2009, FJ 11) 
de poder, o si se prefiere, ejercicio de funciones constitucionales en cuyo acceso, además, no entran en juego solo los méritos y capacidades de las personas candidatas sino también, como hemos mostrado en la primera parte de este texto, los diferentes intereses de los legitimados para proponerlas. Existe pues un margen de discrecionalidad, política por qué no decirlo, en el que debería actuar efectivamente el principio de paridad como criterio rector. En este caso, además, al no tratarse de una institución cuyos miembros sean elegidos directamente por la ciudadanía, no entrarían en juego argumentos que la doctrina ha usado para oponerse a las acciones afirmativas en el ámbito de la ley electoral, tales como la indivisibilidad del cuerpo electoral o la ruptura con el estricto principio de igualdad formal en el ejercicio del sufragio ${ }^{75}$.

Este posicionamiento invalida por tanto cualquier objeción crítica basada en la misma naturaleza del TC, ya que no estamos hablando de mecanismos correctores de la representación ni de medidas antidiscriminatorias que operen en el ámbito de la política, sino que estamos planteando de qué manera debería articularse la composición y el funcionamiento de cualquier instancia pública. Y nadie puede negar que el TC lo es y que, además, constituye un evidente y necesario poder en un Estado constitucional. No se trata, por tanto, y tal como argumentó la STC 12/2008, de aplicar la lógica de la igualdad sustantiva y de las acciones positivas que derivan de ella, sino de redefinir el espacio público y con él la construcción sexuada de la ciudadanía. Un objetivo frente al que el TC, dadas sus funciones, tiene mucho que decir, dado su papel de guardián e intérprete de la Constitución, así como de, en nuestro caso, garante último de los derechos fundamentales. Es decir, si el TC no se limita a «defender la Constitución», sino que también «suministra criterios y principios para la promoción de los valores, derechos y otros bienes constitucionalmente protegidos ${ }^{76}$, parece obligado reconocer que la igualdad de género debiera constituir un criterio principal tanto en su composición como transversalmente en su funcionamiento y toma de decisiones ${ }^{77}$. Ello no sería sino consecuencia de admitir que mujeres y hombres deben formar parte tanto del poder constituyente como de los poderes constituidos, lo cual supone reconocer a ambos

75 Veánse en este sentido los argumentos utilizados por el magistrado Rodríguez Zapata en el voto particular formulado a la STC Sentencia 12/2008, de 29 de enero de 2008.

${ }^{76}$ García Roca, J. (2008), «La experiencia de veinticinco años de jurisdicción constitucional en España», en PÉrez Tremps, P. (coord.), La reforma del Tribunal Constitucional. Actas del V Congreso ACE, Tirant lo Blanch, Valencia, p. 35.

77 Por lo tanto, cobra todo su sentido, también con respecto al TC, lo que el magistrado Pérez Tremps apuntaba en su voto particular a la STC 13/2009 con respeto a otro tipo de órganos: «puede resultar constitucionalmente proporcionado adoptar medidas tendentes a garantizar que las sensibilidades de los dos sexos están presentes en los órganos que tienen que seleccionar a los componentes de las Administraciones públicas o que conceder premios, subvenciones, etc». Si esto es así en órganos que han simplemente de seleccionar personal o conceder premios, mucho más en el caso de un órgano que es el máximo intérprete de la Constitución . 
como «sujetos con igual capacidad y autoridad para ejercer el poder ${ }^{78}$. Solo desde este equivalente reconocimiento será posible superar grave déficit de legitimidad que, desde el punto de vista del género, continúan arrastrando los sistemas constitucionales $^{79}$.

Se trataría, nada más y nada menos, que aplicar el conocido como mainstreaming de género a la composición y funcionamiento del TC, teniendo en cuenta que su actividad, aún no siendo un órgano representativo ni formar parte de los tres poderes clásicos del Estado, puede encuadrarse dentro de los «procesos políticos» que dotan de contenido a un Estado constitucional. En este sentido, la definición que el Consejo de Europa ofrece de dicho término habla expresamente de «la (re)organización, la mejora, el desarrollo y la evaluación de los procesos políticos» ${ }^{80}$. Es decir, cuando hablamos de mainstreaming de género no solo debemos pensar de manera exclusiva en las instancias representativas, o en los órganos de gobierno, sino que ha de entenderse como un criterio que transversalmente presida la actuación de cualquier instancia pública, incluidos también por ejemplo los Tribunales de Justicia y, cómo no, dada sus relevantes funciones, el mismo TC. El art. 15 LOIMH lo deja bien claro cuando señala que «el principio de igualdad de trato y oportunidades entre mujeres y hombres informará, con carácter transversal, la actuación de todos los Poderes Públicos».

Estas lecciones básicas de democracia deberían tenerlas presentes los partidos políticos en el momento de hacer sus propuestas de personas candidatas a la más alta magistratura del país. La «anormalidad democrática», como la calificaba la RFDC, en que ha sobrevivido el TC en sus más de 30 años de funcionamiento, debería subsanarse en aplicación de los mandatos de igualdad indicados. Unos mandatos que deberían ser especialmente rigurosos ante un órgano que tiene entre otras funciones la de decidir cuando una ley es o no constitucional, además de que actúa como último garante de nuestros derechos fundamentales a través del recurso de amparo. El «peso» constitucional de estas funciones bastaría para que fuese más que evidente la necesidad de su composición paritaria ${ }^{81}$. De ahí que, por ejemplo, no se entienda que hayamos puesto correctivos para que el Parlamento tenga una composición equilibrada de

78 Rubio Castro, A. (2013), Las innovaciones en la medición de la desigualdad, Dykinson, Madrid, p. 146 .

79 Así se puso de manifiesto, por ejemplo, hace ya un par de décadas, en la Recomendación del Consejo de 2 de diciembre de 1996, relativa a la participación equilibrada de las mujeres y los hombres en los procesos de toma de decisión, que se dirige a los Estados miembros a fin de que adopten «una estrategia integrada de conjunto destinada a promover la participación equilibrada de las mujeres y de los hombres en los procesos de toma de decisiones y a desarrollar o crear a tal efecto las medidas adecuadas, tales como, en su caso, medidas legislativas, y/o reglamentarias y/o incentivación»

${ }^{80}$ Consejo de Europa (1998), Gender mainstreaming. Conceptual framework, methodology and presentation of good pratics, Consejo de Europa, Estrasburgo.

${ }^{81}$ Véanse en este sentido las reflexiones de Torres, C. (2016), «Las mujeres en y ante el Tribunal Constitucional», Agenda pública, 20 de diciembre de 2016, http://agendapublica.es/las-mujeres-en-y-ante-el-tribunal-constitucional/ (consultada: 13/02/17) 
mujeres y hombres, mientras que dejamos que el Tribunal Constitucional — que con frecuencia actúa como un «legislador negativo» ${ }^{82}$ - siga ocupado mayoritariamente por varones. Como tampoco parece coherente que demos por buenos determinados equilibrios que debe, o debería más bien, reflejar el órgano — por ejemplo, territoriales-y cuestionemos que debe introducir algún correctivo para que su composición sea también equilibrada desde el punto de vista del género ${ }^{83}$.

Se trata, insisto, de una reivindicación que deriva del mismo derecho de ciudadanía que tienen las mujeres pero también de la necesidad de que todas las instancias públicas reflejen las múltiples miradas que pueden hacerse sobre la sociedad que vivimos. De ahí que la paridad, también en el Tribunal Constitucional, acabe siendo garantía de mayor justicia social y de respuestas más ajustadas a una realidad marcada por las relaciones de género. Por lo tanto, la propuesta de un Tribunal Constitucional paritario no sería sino expresión de un «nuevo constitucionalismo» que implica redefinir los sujetos del poder y los fundamentos de éste ${ }^{84}$. O, dicho de otra manera, que supone un nuevo modelo de «pacto social» en el que mujeres y hombres compartamos en condiciones de igualdad tanto el poder constituyente como los constituidos $^{85}$.

\section{CONCLUSIONES Y PROPUESTAS}

1. $\left.{ }^{a}\right)$ Los «peores augurios», en todos los sentidos que hemos explicado en las páginas anteriores, se cumplieron en la última y reciente renovación de magistra-

${ }^{82}$ En este sentido, puede resultar hasta paradójico que se haya previsto la necesidad de medir el «impacto de género» en los proyectos de Ley (art. 26.1.f Ley 50/1997, de 27 de noviembre) y no se cuestione que el TC continúe siendo un órgano mayoritariamente masculino y con respecto al cual no se haya planteado cómo integra la perspectiva de género en el ejercicio de sus funciones.

83 En concreto, en el FJ 8 de la STC 12/2008, de 29 de enero, se dejaba claro que «una representación política que se articule desde el presupuesto de la división necesaria de la sociedad en dos sexos es perfectamente constitucional, pues se entiende que ese equilibrio es determinante para la definición del contenido de las normas y actos que hayan de emanar de aquellos órganos. No de su contenido ideológico o político, sino del precontenido o sustrato sobre el que ha de elevarse cualquier decisión política: la igualdad radical del hombre y de la mujer.»

${ }^{84}$ Rubio Castro, A. (2013), cit., p. 134.

${ }^{85}$ Lo cual no implica, obviamente, cuestionar los méritos y las capacidades que tanto hombres como mujeres candidatos a ocupar un puesto en el TC deberían avalar en sus procesos de selección. Pero se trataría en todo caso de una «competencia» que habría de valorarse a partir del presupuesto ineludible de que el órgano refleje las dos mitades de la ciudadanía. No partir de este presupuesto supondría, entre otras cosas, reconocer que no hay mujeres juristas con la suficiente capacidad para ocupar los mismos lugares relevantes que ocupan su colegas varones. Insistimos, no se trata de reivindicar el plusvalor ideológico, ético o político que puedan tener las mujeres, las cuales tienen derecho a demostrar las mismas capacidades e incapacidades que los hombres, sino de reconocer el derecho subjetivo de cualquier mujer a participara en los procesos de toma de decisiones en equivalentes condiciones a los ciudadanos. 
dos/as que correspondía realizar al Senado. La renovación siguió las pautas de un guión que desde hace años los partidos políticos dominan en nuestro país: a) Hubo un retraso en la renovación; b) La lógica partidista prevaleció sobre la territorial: La propuesta de magistrados/as respondió a un acuerdo entre los dos partidos mayoritarios que, además, en una total perversión del procedimiento previsto, llegaron a presentar las mismas propuestas en la mayoría de Asambleas autonómicas ${ }^{86}$; c) Las comparecencias parlamentarias de las personas candidatas no superaron la mera formalidad expositiva de las trayectorias de los hombres y mujeres propuestos, a los que solo una persona de la Comisión, la representante de ERC, planteó algunas preguntas. Los representantes del resto de grupos se limitaron a agradecer la exposición de los méritos; d) Desde el punto de vista del equilibro de género, de nuevo hubo un claro predominio masculino. De un total de 15 personas candidatas que llegaron al Senado, solo 5 eran mujeres. La propuesta definitiva volvió a dejar a las mujeres en minoría al incorporarse solo como magistrada la catedrática M. ${ }^{a}$ Luisa Balaguer.

2. ${ }^{\text {) }) ~ N o ~ c r e o ~ q u e ~ l a ~ m a y o r i ́ a ~ d e ~ l o s ~ p r o b l e m a s ~ q u e ~ a f e c t a n ~ a ~ n u e s t r o ~ T C ~ p u e d a n ~}$ resolverse mediante reformas legales. No hay que olvidar, además, que muchas de las reformas llevadas a cabo se hayan hecho más en atención a las exigencias políticas del momento que atendiendo a un riguroso análisis sobre las deficiencias del TC y al necesario consenso entre las distintas fuerzas políticas. Salvo cuestiones muy puntuales que han sido planteadas en los últimos años por la doctrina ${ }^{87}$, y que en muchos casos no serían fácil de alcanzar el debido consenso para acometer la reforma de la LOTC y no digamos de la misma $\mathrm{CE}^{88}$, las soluciones tendrían que venir de la mano

86 Debemos recordar que el Parlamento de Cataluña no presentó ninguna propuesta, así como que las Cortes Valencianas se separaron de las «directrices» dominantes y apostaron por dos mujeres, las candidatas d. ${ }^{a}$ María Alicia Millán Hernández y D. ${ }^{a}$ Susana Gisbert Grifo.

87 Sirva como ejemplo la interpretación que propone I. Borrajo para evitar las irregularidades que se producen en las renovaciones de los magistrados, consistente en realizar aquéllas siempre tres años después de finalizada la anterior, lo cual permitiría conjugar mejor los tres criterios establecidos en el apartado 3 del art. 159 CE. Borrajo InIESTA, I. (2013), cit., p. 64.

88 Véanse por ejemplo algunas de las propuestas que plantea J. García Roca, tales como derogar la prorrogatio de los Magistrados constitucionales en el ejercicio de sus funciones (art. 17.2 LOTC), introducir en los Reglamentos de las cámaras una cláusula que obligue a sus servicios jurídicos a mantener permanentemente actualizada una lista de candidatos; prever en la LOTC que el Presidente del TC venga obligado a aceptar la renuncia de los Magistrados y, en los Reglamentos parlamentarios, que las Cámaras deberán proceder a su sustitución en idéntico plazo; regular en la LOTC que las vacantes producidas por muerte, enfermedad o incapacidad de cualquier tipo abran inmediatamente el mecanismo de sustitución en el plazo de un mes; considerar inconstitucional, y por tanto derogable, el mandato final del art. 16.5 LOTC; recuperar el consenso en las designaciones parlamentarias, recobrando el sentido integrador de las mayorías cualificadas o suprimir la renovación escalonada y proceder a una elección conjunta de los Magistrados. García RocA, J. (2010), cit. , pp. 40-41. Mucho más compleja en la práctica me parece por ejemplo la reforma del art. 159 CE que propone García Couso, S. (2012), cit. Pp. 433-456. Sobre las dificultades que en la práctica plantearían estas reformas véase MiLIONE FUGA- 
de una mayor lealtad institucional de los partidos y de la extensión de unos hábitos políticos que hoy por hoy están lejos de ser los dominantes. Partiendo de que ningún sistema de elección es perfecto, habría que lograr un punto intermedio y razonable, que dependería, insisto, más de los hábitos de nuestros representantes que de las soluciones legales que se nos puedan ocurrir, en el que el TC contara con magistrados y magistradas con un razonable nivel de independencia y con una reconocida competencia como juristas que tienen como misión garantizar la supremacía de la Constitución ${ }^{89}$.

3. $\left.{ }^{a}\right)$ Además de ese cambio en la cultura política, otros aspectos más concretos entrarían de lleno en la necesidad de revisar nuestro pacto constitucional. En este sentido, por ejemplo, la «fallida» intervención de las Asambleas autonómicas en la propuesta de los magistrados a designar por el Senado demuestra no sólo que efectivamente la clave está en la cultura política sino que también, en este supuesto, no tiene sentido darle un determinado papel al Senado que no se corresponde con el papel que desempeña habitualmente ${ }^{90}$. Por eso resultan tan discutibles algunas de las afirmaciones como las que el mismo TC hizo en su sentencia 49/2008 al resolver el recurso planteado contra la reforma que posibilitó dicha participación autonómica: «el carácter de Cámara de representación territorial del Senado puede expresarse y desarrollarse no solo en la organización y funciones del mismo, sino en el ejercicio de todas sus facultades y, concretamente, de la elección de los miembros del Tribunal Constitucional que le corresponden». Y me parecen discutibles porque creo que en este caso el orden de los factores sí que altera el producto. Es decir, habría que hacer primero del Senado una auténtica cámara de representación territorial para luego conectar dicho carácter con su papel en la designación de los magistrados constitucionales ${ }^{91}$. No creo que lo segundo contribuya necesariamente a lo primero.

LI, C. (2013), «¿Quién defiende al defensor? Sobre la renovación del Tribunal Constitucional español», Revista General de Derecho Romano, n. ${ }^{\circ}$ 20, 2013, p. 20.

89 Para garantizar esa independencia, parte de la doctrina considera por ejemplo que un Magistrado o Magistrada del TC no debiera haber estado afiliado a un partido político. Me plantea muchas dudas esta limitación e incluso estimo que más que establecer dicha prohibición lo que habría que garantizar es: a) que hubiera la máxima transparencia sobre la trayectoria de los miembros del TC, de tal manera que la ciudadanía tenga clara sus filiaciones, sean formales o no; b) que se consolide una cultura política que posibilite que, desde la misma propuesta de personas candidatas hasta por supuesto el desarrollo de sus funciones, se actúe con estricta sujeción a la CE y con un elevado sentido de «lealtad institucional».

${ }^{90}$ Como tajantemente afirma J. Pérez Royo (2011), cit, p. 65: «No hay sustitutivos para la reforma del Senado".

${ }^{91}$ En esta línea incluso hay quien ha llegado a plantear que tendría más sentido la intervención en las propuestas de magistradas de la Comisión General de Comunidades Autónomas que la de nombramientos. Sánchez Barrilao, J.F. (2009), cit., p. 421. 
4..$\left.^{a}\right)$ Justo es en esa necesidad de revisión del pacto constitucional donde habría que situar la urgencia de incorporar la paridad como un principio que se proyecte tanto en la parte dogmática como orgánica de nuestra Constitución ${ }^{92}$. Es decir, el Estado español desde el mismo art. 1 CE, debería ser definido no solo como Social democrático y de Derecho, sino también como paritario $0^{93}$. Se trataría por tanto de reforzar jurídicamente los mandatos que, de hecho, ya forman parte de nuestro ordenamiento, pero que en la práctica son reducidos a mera formalidad y en muchos casos ignorados por una cultura política, la de los partidos, que continúa siendo profundamente patriarcal. El objetivo no sería otro que, nada más y nada menos, dotar de contenido real el mandato que entiende que la igualdad sustantiva «es un elemento definidor de la noción de ciudadanía» (STC 12/2008, de 29 de enero, FJ 4. ${ }^{\circ}$ ). Y que ese mandato, en consecuencia, se viera reflejado en todos y cada uno de los órganos e instituciones públicas, con más razón por tanto, dada la relevancia de sus funciones, en el TC. Como bien explica Blanca Rodríguez, «la representación formal o descriptiva tiene importancia en términos de género. La tiene en sí misma por su potencial para legitimar un sistema público originalmente excluyente de las mujeres y, por su potencial simbólico en la construcción de códigos sociales de corte igualitario. Y la tiene también en términos de representación sustantiva. Pues aunque no haya relación de causalidad exacta entre una y otra, sí existe entre ellas una importante relación probabilística, instrumental, de medio a fin. Dicho de otro modo, una mayor presencia de mujeres no es condición suficiente para la adopción de medidas de contenido crítico de género, puede que no sea ni siquiera condición estrictamente necesaria, pero aumenta la posibilidad de que se adopten tales medidas» ${ }^{94}$.

El principio de paridad obligaría a que el Tribunal Constitucional estuviera compuesto, por mandato constitucional, por un $50 \%$ de magistrados y un $50 \%$ de magistradas. Así debería reflejarse en el art. 159, el cual debería indicar que el TC se compone de 6 magistrados y 6 magistradas ${ }^{95}$ : «El Tribunal Constitucional se compone de 6 magistradas y 6 magistrados, nombrados por el Rey: cuatro a propuesta del Congreso por mayoría de tres quintos; cuatro a propuesta del Senado, con idéntica

92 Sobre la reforma constitucional con perspectiva de género véase ESQUEMBRE CERDÁ, M. (2016), «Las mujeres ante el cambio constitucional. Algunos apuntes desde una perspectiva feminista para una "reforma constituyente" de la Constitución Española», ATLÁNTICAS - Revista Internacional de Estudios Feministas, n. ${ }^{\circ}$ 1, pp. 184-212.

93 RODRÍGUEZ RUIZ, B. (2016), cit., p. 271.

94 RODRÍGUEZ RUIZ, B. (2017), cit., pp. 155-156.

95 También cabría opciones menos «rotundas», tales como establecer un mandato de presencia equilibrada, de acuerdo con criterio establecido en la Disposición Adicional 1. . $\mathrm{LOIMH}$, o bien introducir el criterio de presencia paritaria en los procedimientos de propuesta de candidaturas. Entiendo, sin embargo, que una reforma del texto de 1978 que incluya la paridad como principio constitucional no debería renunciar a una fórmula paritaria como la propuesta. Opta por un criterio de presencia equilibrada Gómez Fernández, I. (2017), p. 168. En concreto, esta constitucionalista incluye entre los aspectos que deberían ser objeto de reforma constitucional «la garantía de presencia equilibrada de hombres y mujeres en el Consejo General del Poder Judicial y en el Tribunal Constitucional». 
mayoría; dos a propuesta del Gobierno, y dos a propuesta del Consejo General del Poder Judicial». Para garantizar la composición paritaria del Pleno, podría añadirse al art. 159.1 la siguiente previsión: «Cada una de estas propuestas deberá ser paritaria desde el punto de vista del género». Por lo tanto, el Congreso y el Senado deberían proponer 2 hombres y 2 mujeres, y el Gobierno y el CGPSJ un hombre y una mujer cada uno de ellos.

Esta reforma, y la consiguiente de la LOTC, debería conllevar alguna disposición transitoria que permitiera, en las próximas renovaciones, equilibrar la presencia de hombres y mujeres, condicionando por tanto la propuesta de candidaturas por parte de los distintos sujetos legitimados para ello. Igualmente debería introducirse el mainstreaming de género en el control que la Comisión de Nombramientos del Senado realiza sobre la trayectoria de las personas candidatas propuestas por las Asambleas Autonómicas. En este sentido, podría revisarse el apartado $4 .^{\circ}$ del art. 185 del Reglamento del Senado de la siguiente forma: «Durante la comparecencia, los miembros de la Comisión podrán solicitar al candidato aclaraciones sobre cualquier extremo relacionado con su trayectoria profesional o sus méritos personales, entre los que serán especialmente relevantes los relacionados con la aplicación de la perspectiva de género en su labor como jurista». Unas previsiones similares deberían introducirse en los procedimientos de valoración de distintas candidaturas en las distintas instancias con capacidad para hacer propuestas.

Estas reformas deberían ir acompañas de la consiguiente revisión del lenguaje, de manera que se hagan visibles también a las mujeres como miembros del Tribunal. Así, por ejemplo, la redacción del art. 159.2 podría quedar como sigue: «Las magistrados y los magistrados del Tribunal Constitucional deberán ser nombrados entre Magistradas, Magistrados y Fiscales, profesorado universitario, Abogados y abogadas, y personas que formen parte de la Función Pública, todas ellas juristas de reconocida competencia con más de quince años de ejercicio profesional».

Las propuestas anteriores supondrían cumplir de manera efectiva con el mandato constitucional de igualdad, reforzado a su vez por las obligaciones que nos marca el Derecho Comunitario, y supondría un paso decisivo en la definición de «un nuevo pacto social» que otorgue, al fin, plena legitimidad democrática al Estado y sus instituciones. Se trata, nada más y nada menos, que de «pensar en una Constitución, en un texto fundador, que refleje, con mayor exactitud, la materia de la cual está compuesta el ser social. Un ser que, demográficamente hablando, se compone, a partes casi iguales, de hombres y de mujeres ${ }^{96}$.

96 GÓMEZ FERNÁNDEZ, I. (2017), cit., p. 12. 
Title:

The desirable parity composition of the Constitutional Court: A proposal for constitutional reform

\title{
Summary:
}

1. Introduction: Legal Engineering vs. Political Culture. 2. The appointment of men and women judges. 3. The composition of the Constitutional Court from the point of view of Gender. 4. Conclusions and Proposals.

\section{Resumen:}

La progresiva pérdida de prestigio y autoridad del Tribunal Constitucional es consecuencia, entre otros motivos, de un proceso de nombramiento y selección de sus magistrados ciertamente discutibles. Si bien los principales remedios a dicha situación deban venir más de la cultura política que de la ingeniería jurídica, también es cierto que determinadas carencias reclaman simplemente el efectivo cumplimiento de los mandatos legales. Así sucede con el mandato de equilibrio de sexos que la LO 3/2007 dispone para los poderes públicos y que el TC no ha teniendo en cuenta en ninguna de sus renovaciones. Un mandato que deriva a su vez de la necesidad de interpretar nuestro sistema constitucional en términos de democracia paritaria.

\begin{abstract}
:
The progressive loss of prestige and authority of the Constitutional Court is a consequence, among other reasons, of a certainly debatable process of appointment and selection of its judges. Although the main remedies to this situation must come more from the political culture than from legal engineering, it is also true that certain deficiencies simply demand the effective compliance with legal mandates. This is the case with the mandate of «gender balance» that the LO 3/2007 provides for the public authorities and that the Constitutional Court has not taken into account in any of its renewals. A mandate that derives from the need to interpret our constitutional system in terms of parity democracy.
\end{abstract}

\section{Palabras clave:}

Magistrados, legitimidad, Tribunal Constitucional, género, paridad, cultura política.

\section{Key words:}

Magistrates, legitimacy, Constitutional Court, Gender, parity, political culture 